\title{
W-Cu composites with submicron- and nanostructures: progress and challenges
}

\author{
Chao Hou', Xiaoyan Song ${ }^{1}{ }^{1}$, Fawei Tang ${ }^{1}$, Yurong Li', Lijun Cao ${ }^{1}$, Jie Wang ${ }^{1}$ and Zuoren Nie
}

\begin{abstract}
W-Cu composite materials are widely used in civilian industries and aerospace fields owing to their integrated properties of high hardness, wear and arc resistance, electrical and thermal conductivities, and low coefficient of thermal expansion. The recently developed submicron- and nanostructured W-Cu composites exhibit superior performance compared to their conventional coarse-grained counterparts and are expected to further expand applications of this group of materials. This review is focused on recent important progress in the preparation, characterization, and mechanical and physical properties of $\mathrm{W}-\mathrm{Cu}$ composites with refined structures. We summarize the technologies that are capable of refining component structures and evaluate their advantages and limitations. Furthermore, the effects of component refinement and additives such as alloying elements and dispersed particles on the comprehensive performance of $\mathrm{W}-\mathrm{Cu}$ composites are demonstrated. At the end of the review, we propose potential research issues and directions worthy of attention for the future development of W-Cu composites.
\end{abstract}

\section{Introduction}

As a typical bimetal composite, $\mathrm{W}-\mathrm{Cu}$ is called a "pseudoalloy", in which $\mathrm{W}$ and $\mathrm{Cu}$ components do not form a solution or intermetallic compounds. Due to its integrated properties of high hardness and strength, a low thermal expansion coefficient, good arc-resistance arising from $\mathrm{W}$, and high electrical and thermal conductivity from $\mathrm{Cu}, \mathrm{W}-\mathrm{Cu}$ composites offer excellent thermal, electrical, and mechanical performance. This group of materials has been widely applied in civilian industrial fields such as high-voltage electric contact parts, welding electrodes, electronic packaging, and thermal sinks and are also especially demanded in aerospace industries ${ }^{1-4}$. To give full play to their respective advantages and improve the overall performance of the $\mathrm{W}-\mathrm{Cu}$ composite, the ideal microstructure should be composed of interpenetrating $\mathrm{W}$ and $\mathrm{Cu}$ networks with high homogeneity and a high densification degree, as shown by the schematic diagrams in Fig. $1^{5}$.

\footnotetext{
Correspondence: Xiaoyan Song (xysong@bjut.edu.cn)

${ }^{1}$ College of Materials Science and Engineering, Key Laboratory of Advanced Functional Materials, Education Ministry of China, Beijing University of Technology, Beijing 100124, China
}

The mutual insolubility between $\mathrm{W}$ and $\mathrm{Cu}$ arises from a high positive heat of mixing of $35.5 \mathrm{~kJ} \mathrm{~mol}^{-1} 6$. This insolubility is due to their distinct intrinsic features. First, they have different crystal structures: $\mathrm{W}$ is $\mathrm{BCC}$ with an atomic radius of $2.02 \AA$, and $\mathrm{Cu}$ is FCC with an atomic radius of $1.57 \AA$. The difference between their atomic radii is as high as $22 \%$. Second, the electronegativity of W (2.36) is $24 \%$ higher than that of $\mathrm{Cu}(1.9)$; thus, $\mathrm{W}-\mathrm{Cu}$ composites cannot be fabricated by traditional metal-casting processes and must be fabricated by powder metallurgy technologies such as liquid phase sintering and infiltration. Unfortunately, due to the poor solubility and wettability between $\mathrm{W}$ and $\mathrm{Cu}$, it remains difficult to obtain the desired $\mathrm{W}-\mathrm{Cu}$ composites with full densification and a homogenous microstructure, which are essential for desirable high integrative performance.

To enhance the sinterability of $\mathrm{W}$ and $\mathrm{Cu}$ powders, the introduction of active elements such as $\mathrm{Fe}, \mathrm{Co}$, and $\mathrm{Ni}$ has been investigated ${ }^{7,8}$. Nevertheless, those elements lead to deterioration of the electrical and thermal performance. Alternatively, it is also possible to decrease the particle size of $\mathrm{W}$ and $\mathrm{Cu}$ powders to the nanoscale. The nanosized powders have higher surface energy and thus high 


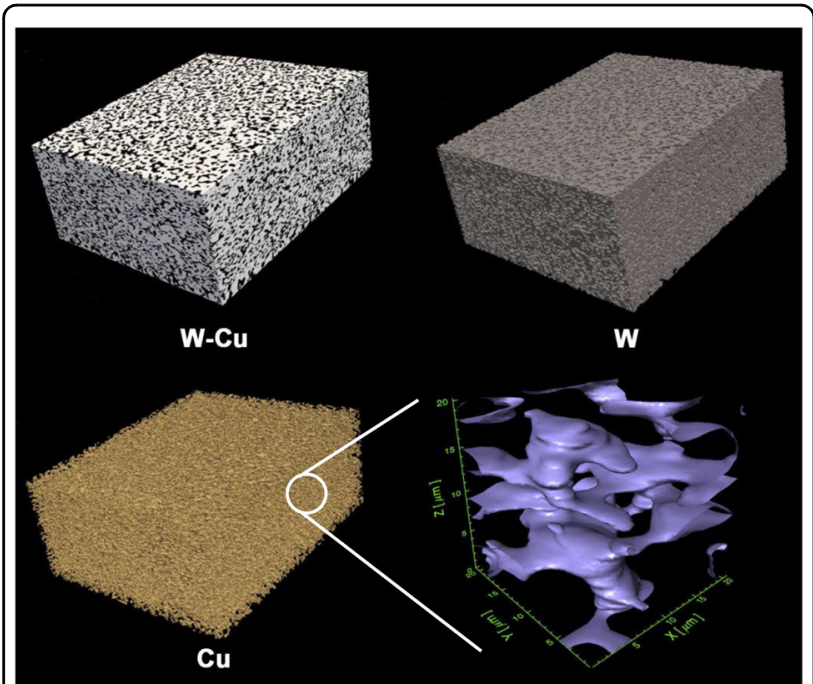

Fig. 1 Three-dimensional reconstruction image of a W-Cu composite; the images on the top-right, bottom-left and bottom-right show the $\mathrm{W}, \mathrm{Cu}$, and the Cu distribution with high resolution, respectively ${ }^{5}$.

activity for sintering densification. In addition, during the process of liquid phase sintering, a higher capillary force can be provided by the rearrangement of $\mathrm{W}$ nanoparticles, which further promotes the densification of the pow$\mathrm{der}^{9,10}$. Apart from improvement of the relative density, $\mathrm{W}-\mathrm{Cu}$ bulk materials prepared by nanopowders have the advantages of a finer and more homogeneous microstructure and thus exhibit significantly improved performance. Recently, a number of new technologies have been developed to prepare $\mathrm{W}-\mathrm{Cu}$ composites with submicronand nanostructures. Moreover, to optimize their comprehensive properties, strategies including the introduction of alloying elements and dispersed particles have been explored for $\mathrm{W}-\mathrm{Cu}$ composite materials.

Here, we review recent progress in submicron- and nanostructured $\mathrm{W}-\mathrm{Cu}$ composites, including fabrication technologies, characterizations of microstructures and various properties. Additionally, modification of the microstructures and properties by the addition of alloying elements and dispersed particles, as well as their influencing mechanisms, is analyzed. This review is expected to provide a systematic summary and evaluation of the important progress in the field of $\mathrm{W}-\mathrm{Cu}$ composites and is considered to be helpful for the future development of advanced $\mathrm{W}-\mathrm{Cu}$ composite materials for high-end applications.

The review is constructed as follows: first, the applications and desired properties of $\mathrm{W}-\mathrm{Cu}$ composites are introduced; second, the fabrication technologies developed for submicron- and nanostructured $\mathrm{W}-\mathrm{Cu}$ composites and the effects of structure refinement on the performance are demonstrated; then, the addition of alloying elements and dispersed particles in the $\mathrm{W}-\mathrm{Cu}$ system, as well as the mechanisms of their effects, is analyzed; and finally, along with a summary, some issues regarding the prospects of and suggested items of interest for the future development of $\mathrm{W}-\mathrm{Cu}$ composites are proposed.

\section{Properties required in applications}

For electrical contact

$\mathrm{W}-\mathrm{Cu}$ composites have been widely used as electrical contact materials in applications such as contactors, switchgears, and breakers ${ }^{11}$. When a switch is connected or disconnected, the electrical contact material suffers from sharp changes in current, arc erosion, and high temperature $^{12} . \mathrm{Cu}$ has a high heat of evaporation of $4770 \mathrm{Jg}^{-1}$. At temperatures higher than its boiling point, $\mathrm{Cu}$ evaporates and takes a large amount of heat, generating a cooling effect on the W skeleton, which is one of the most important advantages of the $\mathrm{W}-\mathrm{Cu}$ composite. However, after a number of switching cycles, $\mathrm{Cu}$ depletion is likely to occur at the contact surface. Thus, the erosion process will change, and the $\mathrm{W}$ skeleton may be densified at high temperatures ${ }^{13}$. With the increasing demand for high-capability electric power systems and extending grids of electric power transmission networks, it is important to develop contact materials that can bear ultrahigh voltages and have long lifetimes ${ }^{12,14}$. That is, the $\mathrm{W}-\mathrm{Cu}$ composites should have high-voltage arc resistance and hightemperature strength and wear resistance while maintaining good electrical and thermal conductivity.

\section{For electronic packaging}

The purpose of electronic packaging is to arrange and assemble components of the integrated circuits to prevent them from the external environment. Owing to the good thermal conductivity, $\mathrm{W}-\mathrm{Cu}$ composites have been used in large-scale integrated circuits and high-power microwave devices as substrates and heat-sinking components $^{3,15}$. Moreover, a suitable thermal expansion coefficient of $\mathrm{W}-\mathrm{Cu}$ composites, which is adjustable by composition, ensures good thermal matching with semiconductor components such as $\mathrm{Si}$ and GaAs in microelectronic devices ${ }^{16}$, thus avoiding the thermal fatigue failure caused by thermal stress. At present, integrated circuitry is developed towards high integration and miniaturization. This means that more concentrated heat needs to be dissipated; thus, there is an increasing requirement for high thermal conductivity of $\mathrm{W}-\mathrm{Cu}$ composites used as electronic packaging materials.

\section{For aerospace industries}

$\mathrm{W}-\mathrm{Cu}$ composites can be applied in aerospace fields, such as parts used in rocket and missile nozzles ${ }^{17} . \mathrm{W}-\mathrm{Cu}$ composites can bear high-temperature loadings where other materials generally lose function. To ensure high 
precision and high reliability in aerospace applications, the strength and ablative resistance of $\mathrm{W}-\mathrm{Cu}$ composites at high temperatures must be improved, in addition to their high electrical conductivity and high arc and wear resistance. Actually, this is a key point to extending hightemperature applications of $\mathrm{W}-\mathrm{Cu}$ composite materials.

\section{Preparation and properties \\ Conventional fabrication technologies}

Infiltration and liquid phase sintering are conventional methods of preparing $\mathrm{W}-\mathrm{Cu}$ composite bulk materials. The liquid phase sintering can be further classified as high-temperature liquid phase sintering and activated liquid phase sintering according to whether or not the elements that facilitate sintering densification are used.

\section{Infiltration}

Infiltration is a predominant conventional technique for preparing $\mathrm{W}-\mathrm{Cu}$ bulk materials because of the relatively high densification degree. In general, the infiltration process contains two steps: prepressing and presintering the micron-scale $\mathrm{W}$ powder into a porous $\mathrm{W}$ skeleton; then, the molten $\mathrm{Cu}$ is allowed to infiltrate and fills in the pores of the W skeleton due to the capillary force ${ }^{15,18}$. Because of the challenges in obtaining the open porosity and uniformity of the skeleton structure, it is difficult to achieve full densification and sufficient homogeneity of the microstructure in the $\mathrm{W}-\mathrm{Cu}$ bulk. As a result, the performance of the material is badly influenced. In addition, infiltration is a time-consuming process, and the bulk materials prepared by infiltration need to be machined to remove the surface $\mathrm{Cu}$-rich layer, which reduces efficiency and increases preparation costs ${ }^{6,15}$. For the infiltration processing of $\mathrm{W}-\mathrm{Cu}$ composites, recent studies have focused on the development of techniques to prepare porous W skeletons with fine structures, highly connected ligaments and open porosity.

\section{Liquid phase sintering}

Liquid phase sintering is an alternative conventional method to prepare $\mathrm{W}-\mathrm{Cu}$ bulk materials, particularly for higher $\mathrm{Cu}$ contents. Generally, liquid phase sintering has three steps: mixing of $\mathrm{W}$ and $\mathrm{Cu}$ powders, cold compression, and sintering at a temperature higher than the melting point of $\mathrm{Cu}$. Compared with infiltration, the advantages of this technique are the simple process and feasible control of the composition. However, the densification degree of liquid phase sintering is generally lower than that of infiltration, e.g., $90-95 \%$ of the theoretical density. Thus, to improve the relative density, subsequent thermal processing is often needed ${ }^{19}$.

Except for additional thermal processing, another effective method to enhance the densification of liquid phase sintering is to introduce some elements (e.g., Co and $\mathrm{Ni}$ ) as sintering activators to improve the sinterability of the powders, due to which the method is called activated liquid phase sintering 9 . Adding an appropriate amount of these sintering activators is beneficial to improving the mechanical properties of the $\mathrm{W}-\mathrm{Cu}$ bulks; however, it reduces the thermal and electrical conductivity of the materials.

Alternatively, taking advantage of the large surface area and high surface energy, decreasing the particle size to nanoscale has been shown to be an effective way to enhance the sinterability of the powders and the density of the resultant $\mathrm{W}-\mathrm{Cu}$ bulks. In addition, considering that the particle rearrangement during sintering depends on the balance between the capillary and bonding forces of W particles, Johnson et al. investigated sintering densification as a function of the particle size (Fig. 2) ${ }^{10}$. It was found that smaller $\mathrm{W}$ particles increase particle rearrangement, hence the as-sintered density, because of the increase in capillary force with the decrease in particle size. The nanopowders facilitate refining the microstructure of sintered bulk materials, thus improving the mechanical properties and arc resistance compared with the traditional coarse-grained $\mathrm{W}-\mathrm{Cu}$ counterparts. Therefore, much effort has been made recently to prepare nanopowders and submicron and nanoscale structures of $\mathrm{W}-\mathrm{Cu}$ composites.

\section{Technologies developed for microstructure refinement Submicron- and nanoporous $W$}

For the fabrication of $\mathrm{W}-\mathrm{Cu}$ composites by infiltration, the feature size and connectivity of ligaments and pores in the porous W skeleton are very important for the microstructure and properties of the final bulk material. When the particle size of $\mathrm{W}$ is reduced to the nanoscale, closed pores are likely to form in the porous W skeleton. In the subsequent infiltration process, the closed pores cannot be filled with liquid $\mathrm{Cu}$; consequently, the density of the prepared composite bulk is lower. However, the preparation of porous $\mathrm{W}$ skeletons with a fine structure and open porosity has been a challenge for years. Shen et al. ${ }^{20}$ fabricated porous $\mathrm{W}$ with a pore size of $\sim 1 \mu \mathrm{m}$ by tape-casting and subsequent sintering. A homogeneous porous structure can be obtained by introducing dispersant and binder, which have the advantages of keeping W powder decentralized in the tape-casting slurry and making the slurry stable and ordered. Furthermore, by introducing $\mathrm{NaCl}$ as a space holder, larger pores of 3-6 $\mu \mathrm{m}$ can be created to form a bimodal distribution of pores in the porous W.

How then can one decrease the feature size of porous $W$ to the nanoscale? It is known that dealloying is an effective method for preparing nanoporous metals. During the dealloying process, chemically active components will be removed from the alloy by the corrosive medium, while 
the remaining component forms a nanoporous structure by atomic diffusion and self-assembly at the solid/liquid interfaces. To date, nanoporous $\mathrm{Au}, \mathrm{Pt}, \mathrm{Ag}$, and $\mathrm{Cu}$ have been successfully prepared by this strategy ${ }^{21}$. Recently, we prepared nanoporous $\mathrm{W}$ with ligament and pore sizes of $\sim 30 \mathrm{~nm}$ by a method combining mechanical alloying and chemical dealloying ${ }^{22}$. It was found that by adjusting the temperature and duration of the subsequent heat treatment, the feature size of porous $\mathrm{W}$ can be modulated to $300 \mathrm{~nm}$ (Fig. 3). Porous W, with a submicron or nanoscale feature size and a high fraction of open porosity, may provide new opportunities for preparing submicron- and nanostructured $\mathrm{W}-\mathrm{Cu}$ composites by infiltration.

\section{Nanoscale W-Cu composite powder}

In recent years, to refine and homogenize the microstructure of $\mathrm{W}-\mathrm{Cu}$ composites prepared by liquid phase

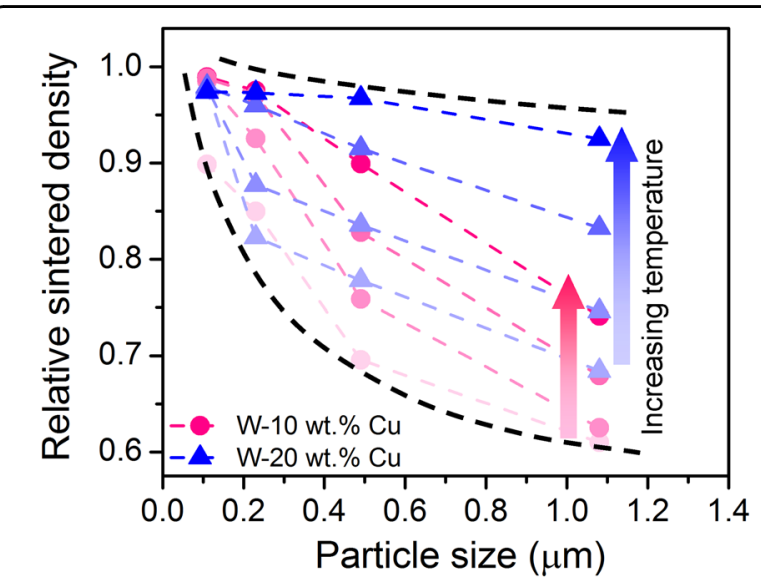

Fig. 2 Relative sintered densities for different temperatures and particle sizes of $\mathrm{W}$ in the $\mathrm{W}-\mathrm{Cu}$ composites $^{10}$.

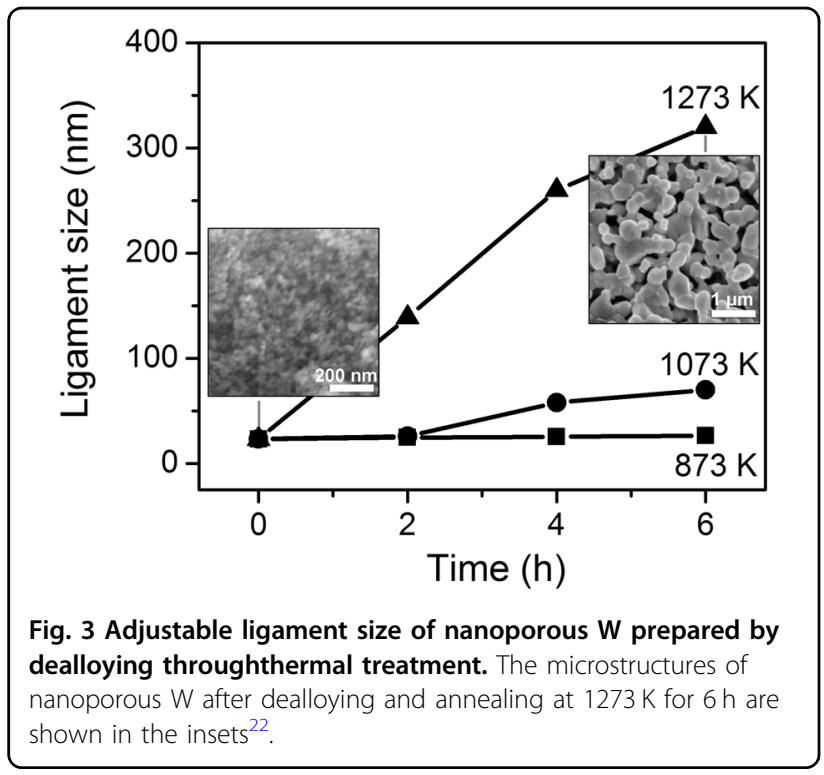

sintering, several methods have been developed to prepare nanoscale $\mathrm{W}$ and $\mathrm{Cu}$ metal powders or $\mathrm{W}-\mathrm{Cu}$ nanocomposite powder as the sintering material. The effect of W particle size on the microstructure and properties of $\mathrm{W}-\mathrm{Cu}$ composites has been investigated ${ }^{23}$. It was found that with decreasing $\mathrm{W}$ particle size, the contiguity of $\mathrm{W}$ grains increased, and the relative density and hardness of the $\mathrm{W}-\mathrm{Cu}$ composite increased due to the improved particle rearrangement and amount of adjacent $\mathrm{W}$ grains. Nevertheless, the proximity of $\mathrm{Cu}$ and thus the electrical conductivity of the composite material decreased slightly. Compared with the $\mathrm{W}-\mathrm{Cu}$ composite prepared using $8 \mu \mathrm{m} \mathrm{W}$ powder, the hardness of the $\mathrm{W}-\mathrm{Cu}$ composite prepared by $400 \mathrm{~nm} \mathrm{~W}$ powder was increased by $84 \%$, with a slight sacrifice of its electrical conductivity (an $11.6 \%$ loss), exhibiting good comprehensive properties in terms of relative density (98.9\%), hardness $(230 \mathrm{HB})$, and electrical conductivity (48.7\% IACS). Moreover, the dielectric breakdown strength of the submicron-grained $\mathrm{W}-\mathrm{Cu}$ composite was increased by $24 \%$ compared with that of the coarse-grained counterpart owing to stronger arc isolation and higher strength of the $\mathrm{W}$ skeleton. The high contiguity of the W skeleton in the ultrafine-grained $\mathrm{W}-\mathrm{Cu}$ composite can be maintained at high temperatures, which is beneficial to its high-temperature performance $^{24}$. A W-25 wt.\% Cu composite with an ultrafine structure was shown to have higher stability, hardness ( 230 HB), and compressive strength during thermal cycling (Fig. 4) and improved wear resistance at higher temperatures compared with the coarse-grained composites. In addition to refining the particle size of the raw powders, there are other methods used for the preparation of $\mathrm{W}-\mathrm{Cu}$ nanocomposite powders, such as mechanical alloying, the mechanical-chemical method, spray drying, sol-gel, and so on.

Mechanical alloying is an effective way to prepare alloys in which the components are not mutually soluble or there exists a large difference between their melting points. In the process of mechanical alloying, $\mathrm{Cu}$ particles suffer from constant flattening and cold welding, while W particles are continuously broken. The grain size decreases, and the interface area increases, which causes the diffusion between $\mathrm{W}$ and $\mathrm{Cu}$ to form $\mathrm{W}-\mathrm{Cu}$ composite powders. Mechanical alloying can promote the solid solubility of $\mathrm{Cu}$ in $\mathrm{W}$ because of the production of a large number of crystal defects (vacancies, dislocations, and stacking faults) in W during high-energy ball-milling. Through diffusion assisted by these crystal defects, a metastable solid solution of $\mathrm{Cu}$ with a certain concentration may be obtained. Moreover, the solid-state sintering activity of the $\mathrm{W}-\mathrm{Cu}$ nanocomposite powders can be improved by mechanical alloying ${ }^{25}$. The sintering shrinkage rates of $\mathrm{W}-\mathrm{Cu}$ powders prepared by simple mixing and mechanical alloying have also been 

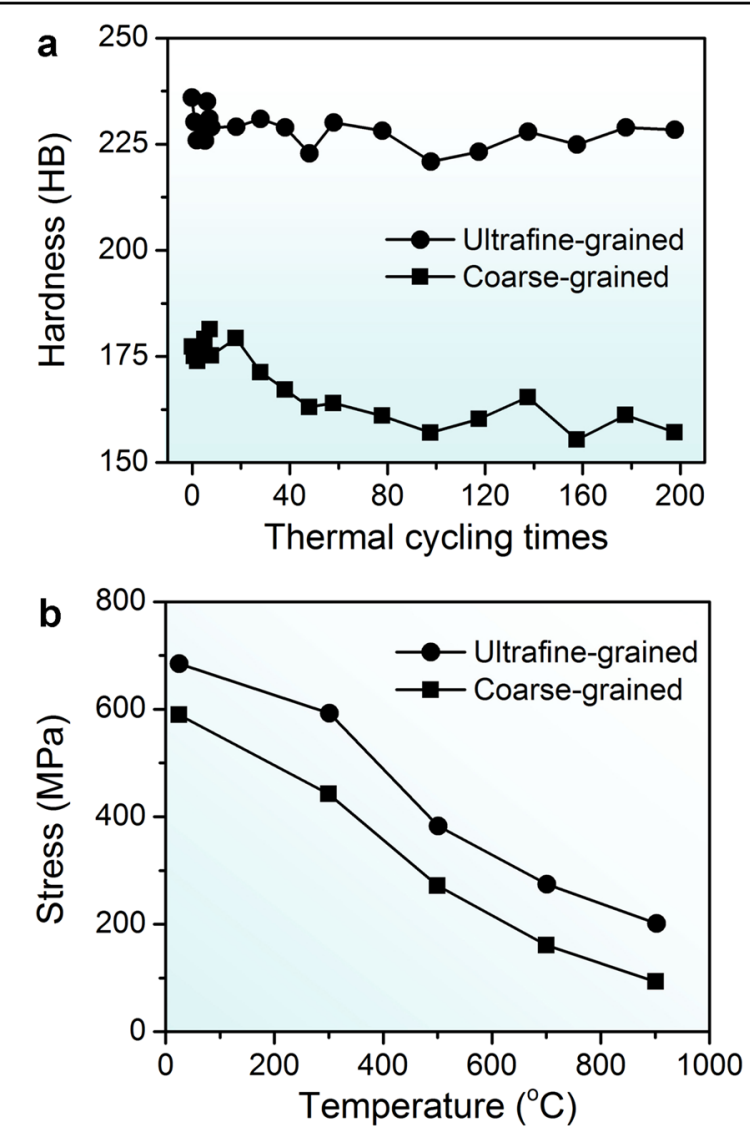

Fig. 4 Mechanical performance variation of W-Cu composites at high temperature by refining microstructure. a Hardness during thermal cycling and $\mathbf{b}$ compressive strength at different temperatures of coarse-grained and ultrafine-grained W-25 wt.\% Cu composites ${ }^{24}$.

compared $^{26}$. There is only one peak at temperatures close to the $\mathrm{Cu}$ melting point in the powder sample prepared by simple mixing of $\mathrm{W}$ and $\mathrm{Cu}$ powders, corresponding to the increased densification due to the rearrangement of $\mathrm{W}$ particles in the molten $\mathrm{Cu}$. By contrast, the sintering curve of the $\mathrm{W}-\mathrm{Cu}$ nanocomposite powder prepared by mechanical alloying has two peaks, one at $950{ }^{\circ} \mathrm{C}$ and another at $1080^{\circ} \mathrm{C}$. This indicates that solid-state sintering, along with liquid phase sintering, plays an important or even dominant role in the sintering densification of the $\mathrm{W}-\mathrm{Cu}$ nanocomposite powder. The enhanced sinterability of the $\mathrm{W}-\mathrm{Cu}$ nanocomposite powder has been attributed to the coupling effect from inside and outside the powder ${ }^{26}$. The interior densification of the individual powder occurred with significant grain growth of the $\mathrm{W}$ nanoparticles $(\sim 20 \mathrm{~nm})$. Simultaneously, $\mathrm{Cu}$ diffused out onto the surface of individual particles, leading to bonding between the composite grain ${ }^{26}$. Taking advantage of the enhanced solid-state sintering, near-fully densified ultrafine $\mathrm{W}-20$ wt.\% $\mathrm{Cu}$ and $\mathrm{W}-30$ wt.\% $\mathrm{Cu}$ bulk materials were prepared at a lower temperature of $1100{ }^{\circ} \mathrm{C}^{27}$.
Nevertheless, the flattening and cold welding of Cu during mechanical alloying has adverse effects on the dispersion of $\mathrm{Cu}$ in the composite, and a longer processing time is required.

To solve this problem, a mechanical-chemical method has been proposed. This method contains mechanical milling of $\mathrm{W}$ and $\mathrm{Cu}$ oxides followed by thermal hydrogen reduction. Due to the brittleness of oxides, a homogenous distribution of $\mathrm{W}$ and $\mathrm{Cu}$ components can be obtained by milling. The dispersion of $\mathrm{W}$ and $\mathrm{Cu}$ particles has a significant influence on the sinterability of the powders, hence the microstructure of the sintered composite bulk $^{28}$. Ball milling over a long time can lead to a microstructure of $\mathrm{Cu}$-coated $\mathrm{W}$ nanoparticles. Because of the difference in the dispersion state of $\mathrm{Cu}$, the composite powders exhibited different sintering behaviors. The $\mathrm{Cu}-$ coated W nanopowder has good sintering characteristics in both solid- and liquid-state sintering. It can reach full density at $1100^{\circ} \mathrm{C}$. However, by liquid-state sintering of the mixed powder with $\mathrm{Cu}$ microparticles, a relative density of $98.9 \%$ was obtained at an even higher temperature of $1200^{\circ} \mathrm{C}$. Although $\mathrm{W}-\mathrm{Cu}$ composites with fine structures can be prepared by mechanical alloying and mechanical-chemical methods, impurities, such as $\mathrm{Fe}$ and $\mathrm{Co}$, are easily introduced in the processing, which causes deterioration of the thermal and electrical properties of the composite material. These impurities limit the application of these methods.

Wet-chemical processes, such as spray-drying, sol-gel, and co-precipitation, were proposed to overcome the contamination problem ${ }^{29-32}$. In the wet-chemical processes, soluble $\mathrm{W}$ and $\mathrm{Cu}$ salts were used as raw materials to synthesize precursors, which were then converted to a $\mathrm{W}-\mathrm{Cu}$ composite powder by calcination and thermal hydrogen reduction. The particle size of the synthesized $\mathrm{W}-\mathrm{Cu}$ composite powder is less than $200 \mathrm{~nm}$, and the grain size of $\mathrm{W}$ is as small as $\sim 35 \mathrm{~nm}$. By liquid phase sintering of this kind of powder, a fine-grained $\mathrm{W}-\mathrm{Cu}$ composite can be obtained; however, the relative density is slightly lower (e.g., $94 \%^{33}$ ). It was argued that the composite powders made from spray-drying were not homogeneous because of the different precipitation rates of $\mathrm{W}$ and $\mathrm{Cu}$ salts during drying. The $\mathrm{Cu}$ content gradually decreased from the outside to the inside of the particle. To solve the problem of non-simultaneous precipitation of $\mathrm{W}$ and $\mathrm{Cu}$ salts, an additional ball-milling treatment was proposed ${ }^{34}$. Furthermore, additional ball milling is also conducive to reducing the temperature for reduction due to the increase in surface area of composite particles and thus improvement of the sinterability ${ }^{35}$. In addition, to control the particle size of the composite powder, a method of freeze-drying has been developed to prepare nanoscale $\mathrm{W}-\mathrm{Cu}$ composite powder. The freezedrying precursors contain tungstate, sulfate, water of 
crystallization, and ammonia with an amorphous structure. After a two-stage thermal reduction, $\mathrm{W}-\mathrm{Cu}$ nanocomposite powder, with a particle size of $10-20 \mathrm{~nm}$, can be produced ${ }^{36}$. The sol-gel method can further improve the uniformity of $\mathrm{W}$ and $\mathrm{Cu}$ in composite powders by introducing complex agents, such as citric acid, which ensure the gradual formation of homogenous gel by hydrolysis and polymerization during the evaporation of water. Using this method, $\mathrm{W}-\mathrm{Cu}$ nanocomposite powder with particle sizes of $100-400 \mathrm{~nm}$ and a homogeneous distribution of composition at the nanoscale can be obtained $^{37,38}$.

\section{Sintering densification}

For traditional methods of sintering $\mathrm{W}-\mathrm{Cu}$ powders, although some processing optimizations have been developed, it is still challenging to achieve a high density while maintaining a nanostructure. In this respect, pressure-sintering and field-assisted sintering techniques have been applied to prepare dense $\mathrm{W}-\mathrm{Cu}$ bulk materials with fine microstructures.

Because hot-press sintering is assisted by pressure, its sintering temperature can be reduced to near the melting point of $\mathrm{Cu}$, and the sintered density can be improved significantly. Additionally, hot-press sintering can also avoid obvious deformation of $\mathrm{W}-\mathrm{Cu}$ composite bulks caused by traditional liquid phase sintering without pressure. Qiu et al. studied the coupling effect of temperature and pressure on the density and hardness of the $\mathrm{W}-\mathrm{Cu}$ bulks prepared by hot-press sintering; the powder made by mechanical alloying was also studied ${ }^{39}$. Under a pressure of $50 \mathrm{MPa}$, the density of the sintered composite increases with the sintering temperature. Given a further increase in the temperature to values higher than the melting point of $\mathrm{Cu}$, liquid $\mathrm{Cu}$ may be extruded from the mold, and the density of the composite will be reduced, as shown in Fig. 5a. At a specific temperature of $1050^{\circ} \mathrm{C}$, the pressure plays an important role in the densification, as shown in Fig. 5b, and the relative density increases from $86.2 \%$ without pressure to $99.2 \%$ at a pressure of $40 \mathrm{MPa}$. Eventually, the density remains nearly unchanged when the pressure is further increased. At the above optimized conditions, the prepared W-20 wt.\% Cu bulk has fewer pores and a microstructure consisting of ultrafine $\mathrm{W}$ grains (with a mean size of $500 \mathrm{~nm}$ ) and a continuous $\mathrm{Cu}$ network (Fig. 5c), and the hardness reaches $310 \mathrm{HV}$, which is more favorable than that prepared by the mixed $\mathrm{W}$ and $\mathrm{Cu}$ powders under less optimized conditions (Fig. 5d).

To further increase the sintering densification while inhibiting rapid grain growth during sintering, fieldassisted sintering methods, which offer the advantages of faster heating and cooling, a lower sintering temperature, and a shorter processing duration, have been developed. Because metal powder can absorb microwave radiation effectively and use eddy current loss for autogenous heating, microwave sintering has been applied to densify different kinds of metal powders ${ }^{40}$. It has been shown that microwave sintering promoted the densification of $\mathrm{W}-\mathrm{Cu}$ compacts at a heating rate of $40^{\circ} \mathrm{C} / \mathrm{min}$, and a near-theoretical density was realized ${ }^{41}$. In addition, a homogeneous microstructure was formed in the $\mathrm{W}-\mathrm{Cu}$ composite prepared by microwave sintering, compared with $\mathrm{W}$ aggregation and large $\mathrm{Cu}$ pools formed in the conventional liquid-phase-sintered counterparts. By microwave sintering, Zhou et al. ${ }^{37}$ prepared W-15 wt.\% $\mathrm{Cu}$ bulks using nanocomposite powder synthesized by the sol-gel method. The $\mathrm{W}-\mathrm{Cu}$ composites sintered at $1200^{\circ} \mathrm{C}$ had an average W grain size of $600 \mathrm{~nm}$ and a relative density higher than $97 \%$. Their hardness and thermal conductivity were $347 \mathrm{HV}$ and $187 \mathrm{~W} / \mathrm{mK}$, respectively. A more compact distribution of $\mathrm{W}$ and higher density may be achieved by applying pressure during microwave sintering ${ }^{42}$.

Spark plasma sintering (SPS) has been considered one of the most popular fast thermal densification methods. In the SPS process, the particle surfaces are activated, and the sintering temperature can be significantly reduced ${ }^{43}$. Elsayed et $\mathrm{al}^{44}$. compared the effects of SPS and conventional liquid phase sintering on the microstructure and properties of prepared $\mathrm{W}-\mathrm{Cu}$ bulk materials. It was found that the $\mathrm{W}-\mathrm{Cu}$ samples sintered by SPS had better mechanical properties because of the finer microstructure and stronger combination of $\mathrm{W}$ particles; however, the maximum relative density of the SPS samples was only $90 \%$. Later, in a work on a spark-plasma-sintered W-30 wt.\% $\mathrm{Cu}$ bulk sample, a mean $\mathrm{W}$ grain size of less than $400 \mathrm{~nm}$ and a maximum relative density of $97.3 \%$ were obtained at a sintering temperature of $950{ }^{\circ} \mathrm{C}$ and a pressure of $120 \mathrm{MPa}$, as shown in Fig. 6. The nanocomposite powder synthesized by the sol-gel method was used as the sintering material. At temperatures below $990^{\circ} \mathrm{C}$, the relative density and homogeneity of the assintered composites increased with increasing temperature and pressure. The prepared material had a thermal conductivity of $235.48 \mathrm{~W}(\mathrm{~m} \mathrm{~K})^{-1}$ and a relatively lower thermal expansion coefficient (CTE) of $9.27 \times \mathrm{ppm} \mathrm{K}^{-138}$.

\section{Severe plastic deformation}

The method of severe plastic deformation has been used to refine the microstructures of coarse-grained $\mathrm{W}-\mathrm{Cu}$ bulk materials. Sabirov et al. prepared a W-25 wt.\% Cu material with a mean grain size of $10-20 \mathrm{~nm}$ by applying high-pressure torsion to coarse-grained $\mathrm{W}-\mathrm{Cu}$ composites with grain sizes of $2-10 \mu \mathrm{m}^{45}$. With increasing load, the grain structure of the $\mathrm{W}-\mathrm{Cu}$ composites can be refined; moreover, the temperature in the torsion process played a significant role in the microstructure evolution of 

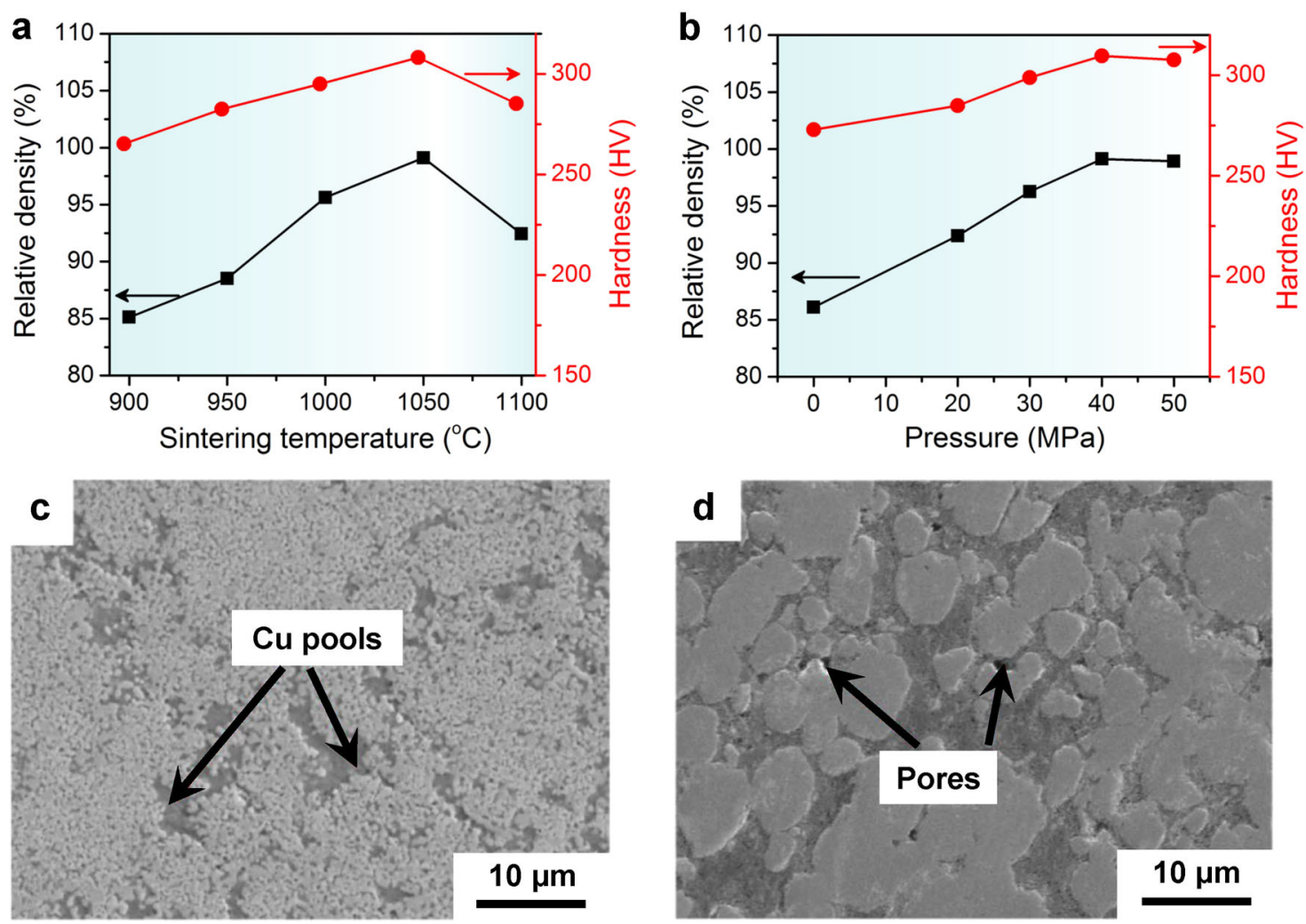

Fig. 5 Coupling effect of temperature and pressure on the density, hardness and microstructure of W-Cu composite consolidated by hotpress sintering. Relative density and hardness of the sintered $\mathrm{W}-\mathrm{Cu}$ composites with temperature at a constant pressure of $50 \mathrm{MPa}$ (a) and with pressure at a temperature of $1050^{\circ} \mathrm{C}(\mathbf{b})$. The microstructures of the sintered W-Cu composites from (c) nanostructured W-Cu powder and (d) conventional mixed W-Cu powder ${ }^{39}$.

the composite. Increasing the temperature at which torsion is performed can lead to coarsening of the $\mathrm{W}-\mathrm{Cu}$ nanocrystalline structure; thus, strong plastic deformation and low deformation temperature are dominant for a nanostructure.

\section{Evaluation of methods for microstructure refinement}

Table 1 summarizes the results of $\mathrm{W}-\mathrm{Cu}$ composites with 15-30 wt.\% $\mathrm{Cu}$ content that have been reported in the literature, including the fabrication methods, grain size of $\mathrm{W}$, and mechanical and physical properties. Compared with the coarse-grained counterparts, in general, the fine-grained $\mathrm{W}-\mathrm{Cu}$ composites have superior hardness; however, there are few evident advantages in their physical properties. Nevertheless, there are some inspiring results showing comparable or even better physical properties of the composites with finer grain size relative to their coarse-grained counterparts. For example, the W-15 wt.\% Cu bulks with a mean grain size of $800 \mathrm{~nm}$ and a relative density of $98 \%$ prepared by SPS using the spray-dried composite powder as the sintering material ${ }^{43}$, or with a mean grain size of $600 \mathrm{~nm}$ and a relative density of $97 \%$ prepared by the sol-gel method and microwave sintering ${ }^{37}$, exhibit a higher thermal conductivity (e.g., $\left.\sim 190 \mathrm{~W}(\mathrm{mK})^{-1}\right)$. The W-30 wt.\% Cu composite, with a mean grain size of $350-400 \mathrm{~nm}$ and a relative density of 97.3\% prepared by the sol-gel method and field-assisted sintering, had a lower CTE of $9.27 \mathrm{ppm} \mathrm{K}^{-1} 38$. Therefore, there is potential to optimize the processing and microstructure, especially in terms of the mutual distribution and connectivity of $\mathrm{W}$ and $\mathrm{Cu}$ in the composite, which is very important for the achievement of excellent physical properties.

As mentioned above, a variety of techniques have been developed for refining the microstructure of $\mathrm{W}-\mathrm{Cu}$ composites. The application of the nanocrystalline $\mathrm{W}-\mathrm{Cu}$ obtained by severe plastic deformation is limited by the dimensions and shape of the operation facility. Moreover, the crystal defects introduced by the deformation process have negative effects on the mechanical and physical properties of the nanocrystalline $\mathrm{W}-\mathrm{Cu}$ bulk materials. For $\mathrm{W}-\mathrm{Cu}$ composites fabricated by infiltration, techniques for preparing submicron- or nanoscale porous $\mathrm{W}$ with open channels have been developed. How then to fill the refined pores with $\mathrm{Cu}$ and avoiding coarsening of the W skeleton during infiltration are key directions for future 

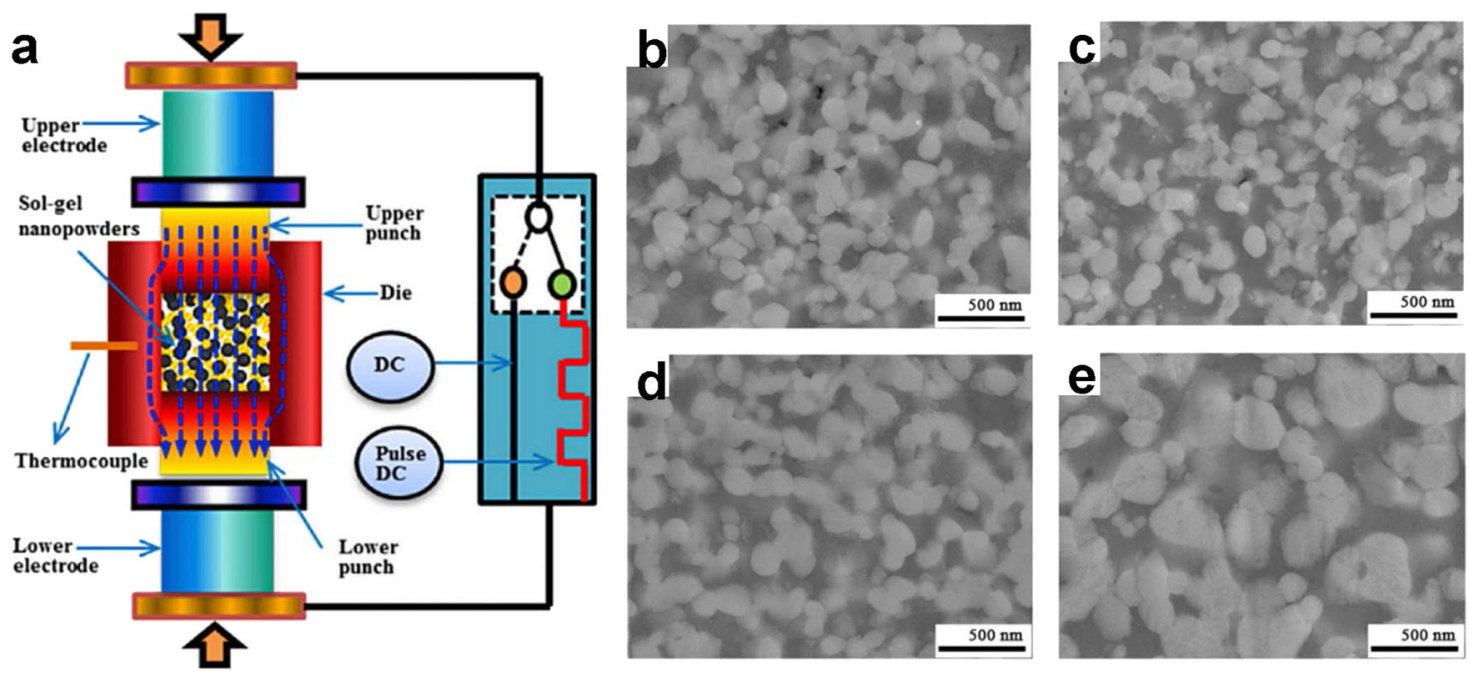

Fig. 6 Microstructure evolution of W-Cu composites consolidated by SPS. a Schematic illustration of SPS densification of W-Cu composite powder. Microstructures of $\mathrm{W}-\mathrm{Cu}$ composites sintered at $\mathbf{b} 850^{\circ} \mathrm{C}, \mathbf{c} 900^{\circ} \mathrm{C}, \mathbf{d} 950^{\circ} \mathrm{C}$, and $\mathbf{e} 990^{\circ} \mathrm{C}$ under a pressure of $120 \mathrm{MPa}$ for $10 \mathrm{~min}{ }^{38}$.

research. For liquid phase sintering, to prepare submicron- and nanostructured $\mathrm{W}-\mathrm{Cu}$ composites, coordination between the synthesis of $\mathrm{W}-\mathrm{Cu}$ nanocomposite powders and sintering densification with control of the grain growth is strongly needed.

Modulation of microstructures and properties by additives

In the section "Preparation and properties", the technologies of preparing $\mathrm{W}-\mathrm{Cu}$ composites, particularly the submicron- and nanostructured $\mathrm{W}-\mathrm{Cu}$ bulk materials, were reviewed, together with the microstructures and mechanical and physical properties of the resultant materials. In that section, attention was paid to the fabrication methods, and the mentioned materials were basically binary $\mathrm{W}-\mathrm{Cu}$ composites. In this section, various additives used in the $\mathrm{W}-\mathrm{Cu}$-based composites, as well as their effects on the modulation of microstructures and performance of the prepared bulk materials, are reviewed in according to the type of additive.

\section{Alloying elements \\ Interaction with $\mathrm{Cu}$}

The effects of alloying elements on $\mathrm{W}-\mathrm{Cu}$ composites can be divided into three categories according to their influences on $\mathrm{W}, \mathrm{Cu}$, and the interfaces between them. Some elements, such as $\mathrm{Zn}$ and $\mathrm{Ag}$, which are insoluble in $\mathrm{W}$, can act as sintering activators by forming a solid solution or compound with $\mathrm{Cu}$ to decrease the temperature for sintering densification and increase the fluidity of the liquid phase, leading to improvement of the relative density and properties of the sintered composite bulks. It was reported by $C$ en et al. ${ }^{46,47}$. that with increasing amounts of $\mathrm{Zn}$ addition, $\mathrm{Cu}-\mathrm{Zn}$ intermetallic compounds formed instead of $\mathrm{Zn}$ dissolution in $\mathrm{Cu}$. The relative density of the composite bulk increased gradually, e.g., at a $\mathrm{Zn}$ content of $2 \mathrm{wt} . \%$, the relative density of the $\mathrm{W}-\mathrm{Cu}-\mathrm{Zn}$ bulk alloy reached $97.9 \%$. The change in the Vickers hardness of the bulk alloy was consistent with the change in the relative density. As shown in Fig. 7, with the increase in $\mathrm{Zn}$ content, the hardness of the alloy bulk first increased and then remained at a certain level and increased significantly only when the $\mathrm{Zn}$ addition was larger than 14 wt.\%. At the non-densification stage (area I), the hardness increased with the $\mathrm{Zn}$ content. At steady stage (II), the hardness remained at $250 \mathrm{HV}$ because the material reached near-full densification.

When the $\mathrm{Zn}$ content was above 14\% (stage III), the hardness increased to $361 \mathrm{HV}$ owing to the formation of $\mathrm{Cu}-\mathrm{Zn}$ intermetallic compounds. Moreover, the room temperature bending strength of the $\mathrm{W}-\mathrm{Cu}-\mathrm{Zn}$ alloy increased with the addition of $\mathrm{Zn}$ and decreased only slightly when the $\mathrm{Zn}$ content was much higher. The maximum bending strength of $960 \mathrm{MPa}$ was obtained when the $\mathrm{Zn}$ content reached the maximum solid solubility in $\mathrm{Cu}$. It was proposed that the addition of $\mathrm{Zn}$ could modulate the interface between $\mathrm{W}$ and $\mathrm{Cu}$ from physical contact to chemical combination, thus changing the fracture mechanism of the composite bulk ${ }^{46,47}$. Without $\mathrm{Zn}$ addition, the mode of fracture was $\mathrm{W}$ particles breaking off from $\mathrm{Cu}$. With $\mathrm{Zn}$ addition, the mode of fracture was mainly transgranular fracture of $\mathrm{W}$ and ductile fracture of $\mathrm{Cu}$. The effects of $\mathrm{Zn}$ on the physical properties of $\mathrm{W}-\mathrm{Cu}$ composites have also been studied. It was found that due to addition of $\mathrm{Zn}$, distortion of the $\mathrm{Cu}$ lattice may occur, leading to more scattering of electrons and phonons; thus, the thermal 


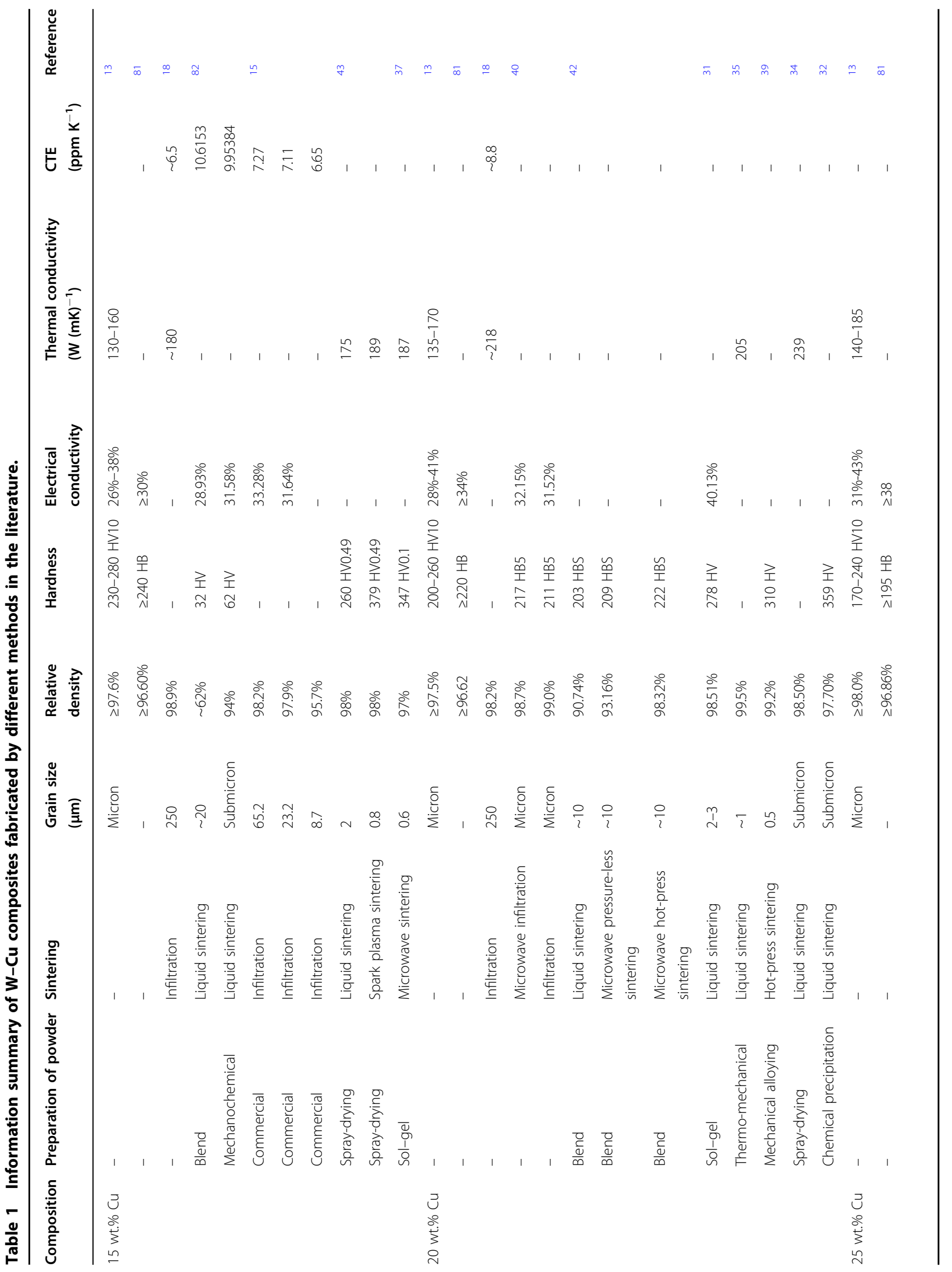




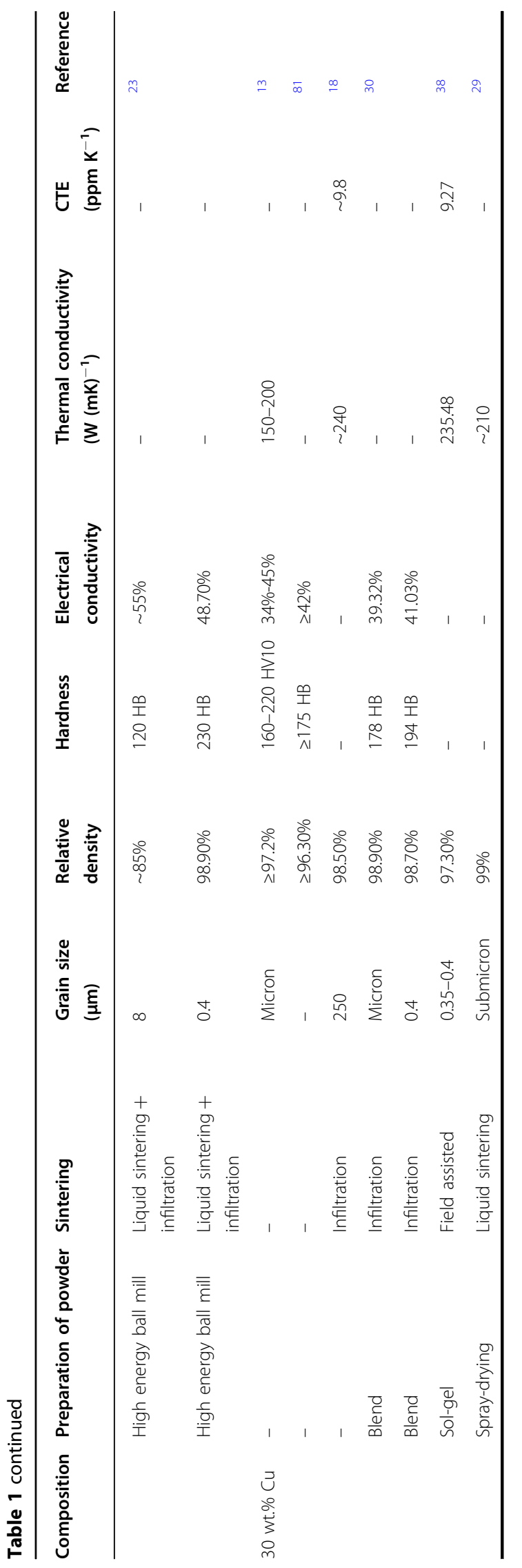

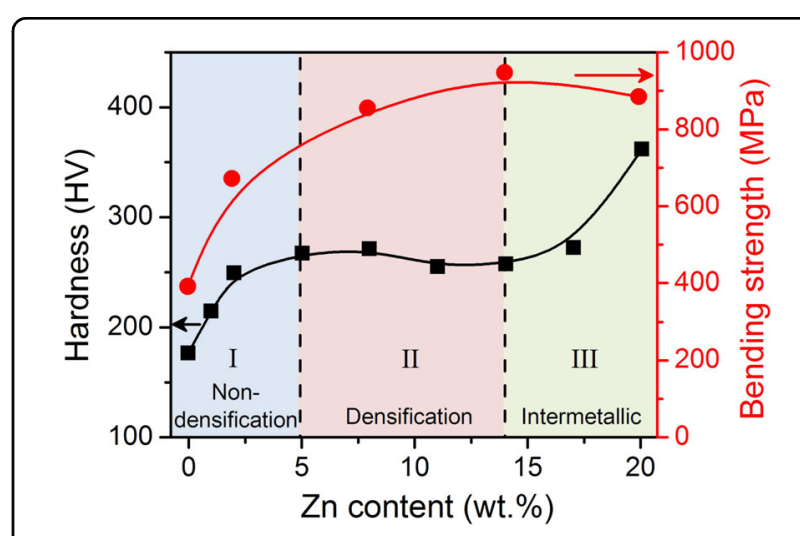

Fig. 7 Changes in Vickers hardness and bending strength of the W-Cu composites with $\mathrm{Zn}$ content ${ }^{46}$.

and electrical conductivity will be decreased ${ }^{48}$. However, the thermal expansion coefficient decreased from $9.56 \times \mathrm{ppm}$ to $8.75 \times \mathrm{ppm} \mathrm{K}^{-1}$ with the addition of $\mathrm{Zn}$ owing to the increase in density.

Azar et al. ${ }^{32,49}$ used a chemical precipitation method that introduced $\mathrm{Ag}$ into the $\mathrm{W}-\mathrm{Cu}$ composite in a homogenous manner and found that the addition of $\mathrm{Ag}$ was beneficial to the improvement in sinterability due to the dissolution of $\mathrm{Ag}$ in $\mathrm{Cu}$. The relative density of the composite bulk reached $98.2 \%$ with 1 wt.\% addition of $\mathrm{Ag}$ and further increased to $99.6 \%$ when the $\mathrm{Ag}$ addition was increased to $10 \mathrm{wt} . \%$. However, because the hardness of $\mathrm{Ag}$ is less than that of $\mathrm{Cu}$, and adding $\mathrm{Ag}$ can reduce the hardness of the composite. In their work, the hardness of the $\mathrm{W}-\mathrm{Cu}-\mathrm{Ag}$ bulk reduced to $255 \mathrm{HV}$ with a $\mathrm{Ag}$ content of 10 wt.\% from $359 \mathrm{HV}$ without Ag.

\section{Interaction with $\mathrm{W} / \mathrm{Cu}$ interface}

Some elements have certain solubility in both $\mathrm{W}$ and $\mathrm{Cu}$. These elements can also diffuse into and act at the $\mathrm{W} / \mathrm{Cu}$ interfaces. In the material in which $\mathrm{Zr}$ was introduced by infiltrating CuZr into the sintered $\mathrm{W}$ skeleton ${ }^{50}$, it was found that $\mathrm{Zr}$ diffused from $\mathrm{CuZr}$ to $\mathrm{W}$ during infiltration, and the remaining $\mathrm{Zr}$ precipitated in $\mathrm{Cu}$ during the subsequent aging treatment. The mass transfer and precipitation of $\mathrm{Zr}$ were beneficial to strengthening both the $\mathrm{W} / \mathrm{Cu}$ interfaces and $\mathrm{Cu}$ phase, while the high electrical conductivity of the $\mathrm{Cu}$ phase was retained. Moreover, the introduction of $\mathrm{Zr}$ can effectively improve the resistance against arc ablation in a vacuum. The effects of $\mathrm{Zr}$ on the improvement in bonding strength and stability of the interfaces were also confirmed by first-principles calculations ${ }^{51}$. 


\section{Interaction with $W$}

The interactions between alloying elements and $\mathrm{W}$ may have distinctly different behaviors. For elements that have solubility in $\mathrm{W}$, e.g., $\mathrm{Co}, \mathrm{Ni}, \mathrm{Fe}$, and $\mathrm{Pd}$, the diffusion and sintering densification of $\mathrm{W}$ can be enhanced by their additions. In particular, Co and Fe can form intermetallic compounds with $\mathrm{W}$, which may act as an atomic diffusion channel that significantly enhances the diffusion of W. As a result, the sintering density, hardness, and strength of the composite bulk will be increased. However, elements such as $\mathrm{Ni}$ and $\mathrm{Pd}$, which are more readily dissolved in $\mathrm{Cu}$, decrease the solubility of $\mathrm{W}$ in $\mathrm{Cu}$ during the sintering process and thus cannot effectively increase the sintering densification and properties of the bulk material at some concentrations ${ }^{52,53}$.

Although a variety of technologies have been developed for refining the microstructure of $\mathrm{W}-\mathrm{Cu}$ composites, apart from severe plastic deformation, the nanostructures of the raw powders can hardly be maintained after sintering, and the grain structure of W eventually coarsens to the submicron- or even micron-scale. To inhibit grain growth of the $\mathrm{W}$ matrix, some elements that have a strong tendency of segregation at W grain boundaries were studied by both experiments and calculations. Schuh and his colleagues developed a hybrid model combining thermodynamic calculations and Monte Carlo simulations to describe the thermal stability of nanostructured alloys $^{54-56}$. Based on their model, a nanostructure stability map of W-based alloys as a function of their segregation and mixing enthalpies was proposed (Fig. 8a), which was used to screen out doping elements that tend to segregate at $\mathrm{W}$ grain boundaries and hence stabilize the nanograin structure $^{57}$. Experimentally, they proved that the addition of Ti can maintain a nanograin structure of $\sim 22 \mathrm{~nm}$ in a W-6 wt.\% Ti alloy at $1100^{\circ} \mathrm{C}$ for as long as one week, exhibiting a superhigh thermal stability (Fig. 8b). The segregation effect of $\mathrm{Ti}$ in the annealed $\mathrm{W}-\mathrm{Ti}$ alloy was confirmed by its distribution, obtained from both simulations and experiments (Fig. 9) ${ }^{58}$, indicating that the thermal stability of the nanograin structure can be significantly enhanced by solute segregation of specific atoms at the grain boundaries.

Ren et al. studied the effect of Ti addition on the densification and grain growth of W powders in the sintering process $^{59}$. The results showed that with 1 wt.\% Ti addition, the mean grain size of $\mathrm{W}$ was decreased by $63 \%$ compared with that without $\mathrm{Ti}$ but with the same sintering density. They found that the sintering atmosphere also had an important effect on the densification and grain size of $\mathrm{W}-\mathrm{Ti}$ powders. Sintering $\mathrm{W}-1$ wt.\% $\mathrm{Ti}$ nanopowder in Ar improved densification with less grain growth compared with sintering the same powder in a $\mathrm{H}_{2}$ atmosphere. The diffusion mechanisms in the process of sintering turned from concurrent volume diffusion and grain boundary diffusion in Ar to vapor transport and volume diffusion in $\mathrm{H}_{2}{ }^{60}$. In addition, Ti plays a role not only in inhibiting grain growth but also in adsorbing oxygen existing in $\mathrm{W}$ powder.

Taking advantage of the effect of Ti segregation at W grain boundaries, a $\mathrm{W}-\mathrm{Cu}$ composite with nanocrystalline $\mathrm{W}$ was recently developed in our work, as the microstructures shown in Fig. 10. The W(Ti)-Cu composite powder was prepared by mechanical alloying of $\mathrm{W}$ and $\mathrm{Ti}$ powders, followed by mixing the $\mathrm{W}(\mathrm{Ti})$ powder with $\mathrm{Cu}$ particles. Within the $\mathrm{W}$ grains, it is observed that the Ti-rich phase distributes at the grain boundaries (Fig. $10 \mathrm{c}-\mathrm{e})$, which effectively inhibits the growth of the W grains.

Based on previous modeling studies on the thermal and phase stabilities of nanocrystalline alloys ${ }^{61,62}$, we proposed
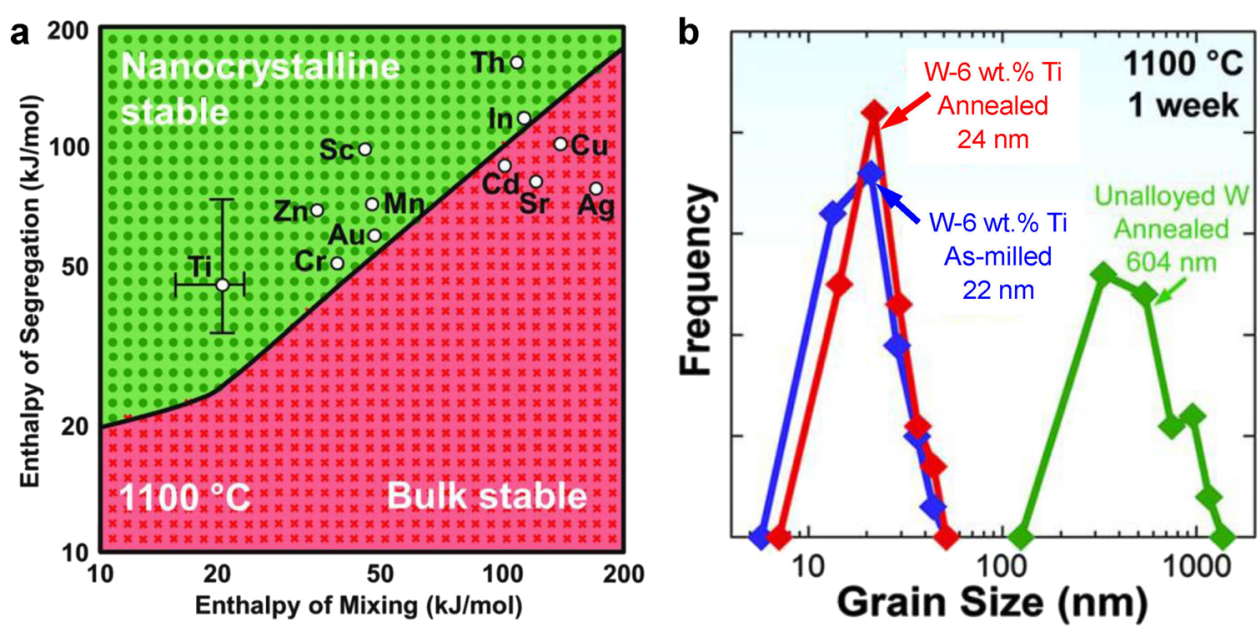

Fig. 8 Thermal stability of nanostructure for W-based alloys. a A nanostructure stability map for W-based alloys, used to screen out doping elements that segregate at the grain boundaries. b Grain sizes of the W- 6 wt.\% Ti alloy before and after one week of annealing at $1100^{\circ} \mathrm{C}^{57}$. 

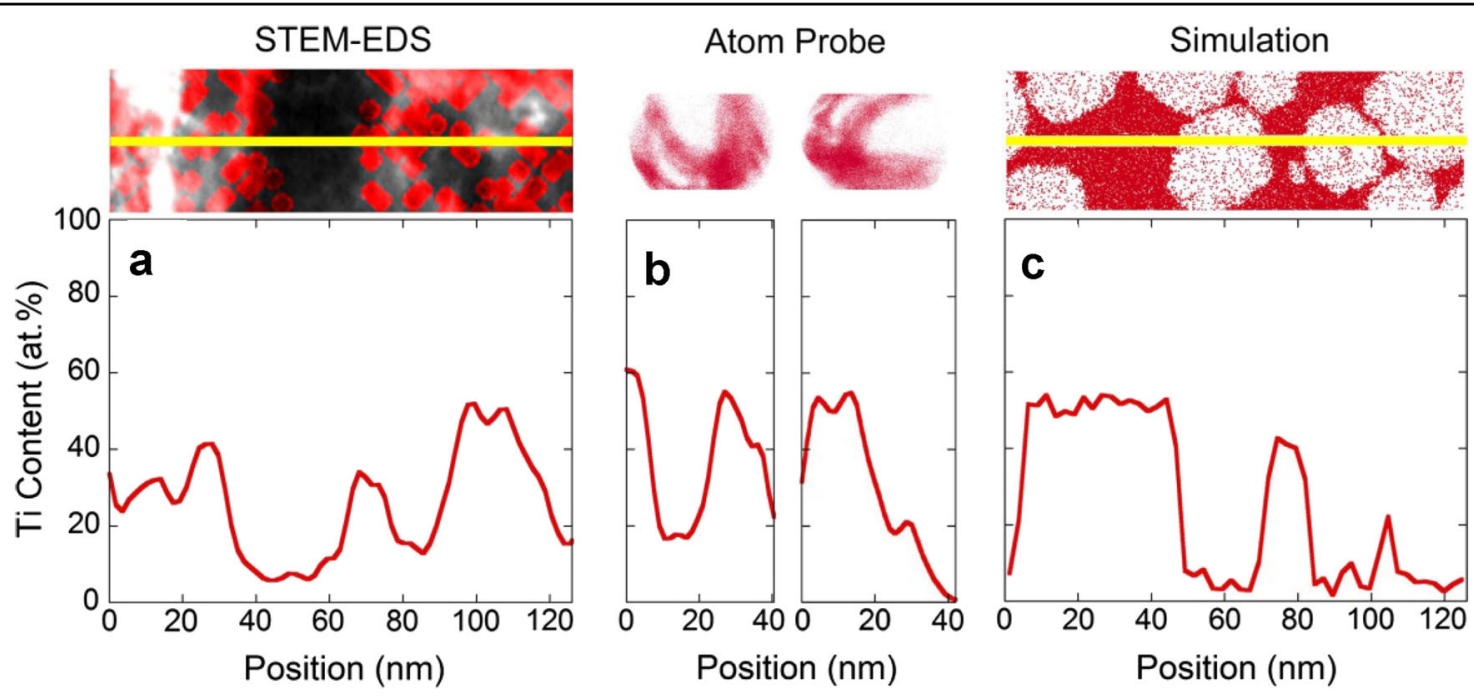

Fig. 9 Distribution of Ti in the W- 6 wt.\% Ti alloy after prolonged annealing, characterized by three independent methods. a STEM-EDS, b Atom Probe, and c Monte Carlo simulation ${ }^{58}$.

a

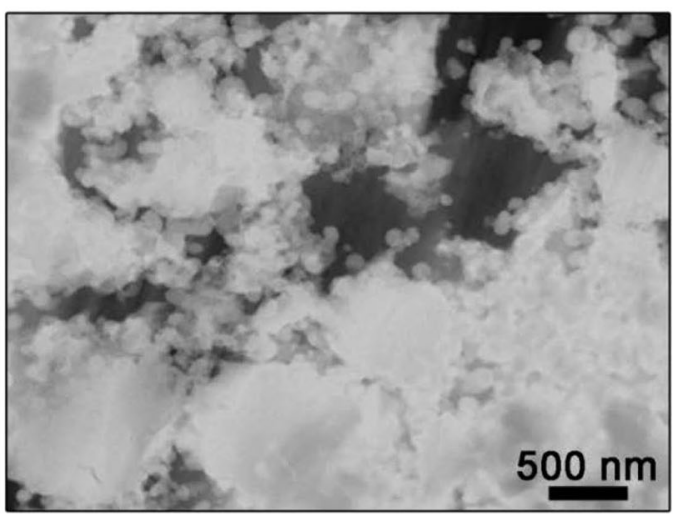

C

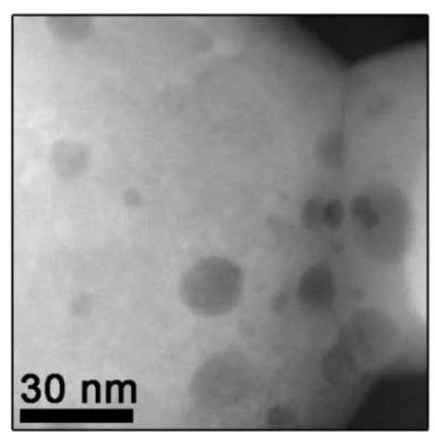

b
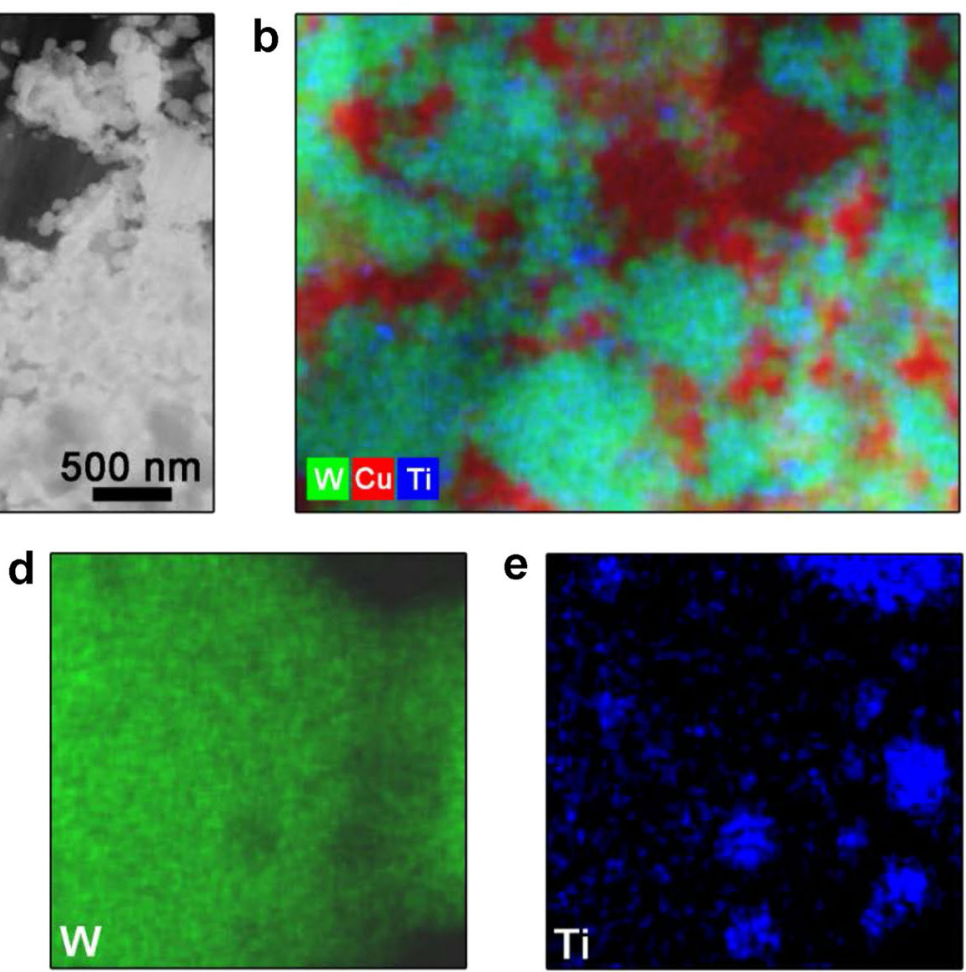

Fig. 10 Characterization of the prepared $\mathbf{W}(\mathrm{Ti})-\mathbf{C u}$ composite. a microstructure, $\mathbf{b}$ element distribution, and $\mathbf{c}-\mathbf{e}$ detailed element distribution maps, showing the Ti distribution mainly at the nanograin boundaries of W.

a model coupling the first-principles and thermodynamics to describe the mechanisms for the stabilization of doped W nanocrystalline alloys ${ }^{63}$. The segregation behavior of doping elements at grain boundaries was quantified, i.e., the segregation enthalpy (Fig. 11a), grain-boundary formation energy (Fig. 11b), and change in the system Gibbs free energy (Fig. 11c) were described as a function of the solute concentration, grain size, and temperature, respectively. It was predicted that to achieve stabilization of the nanograin structure at a certain high temperature, 

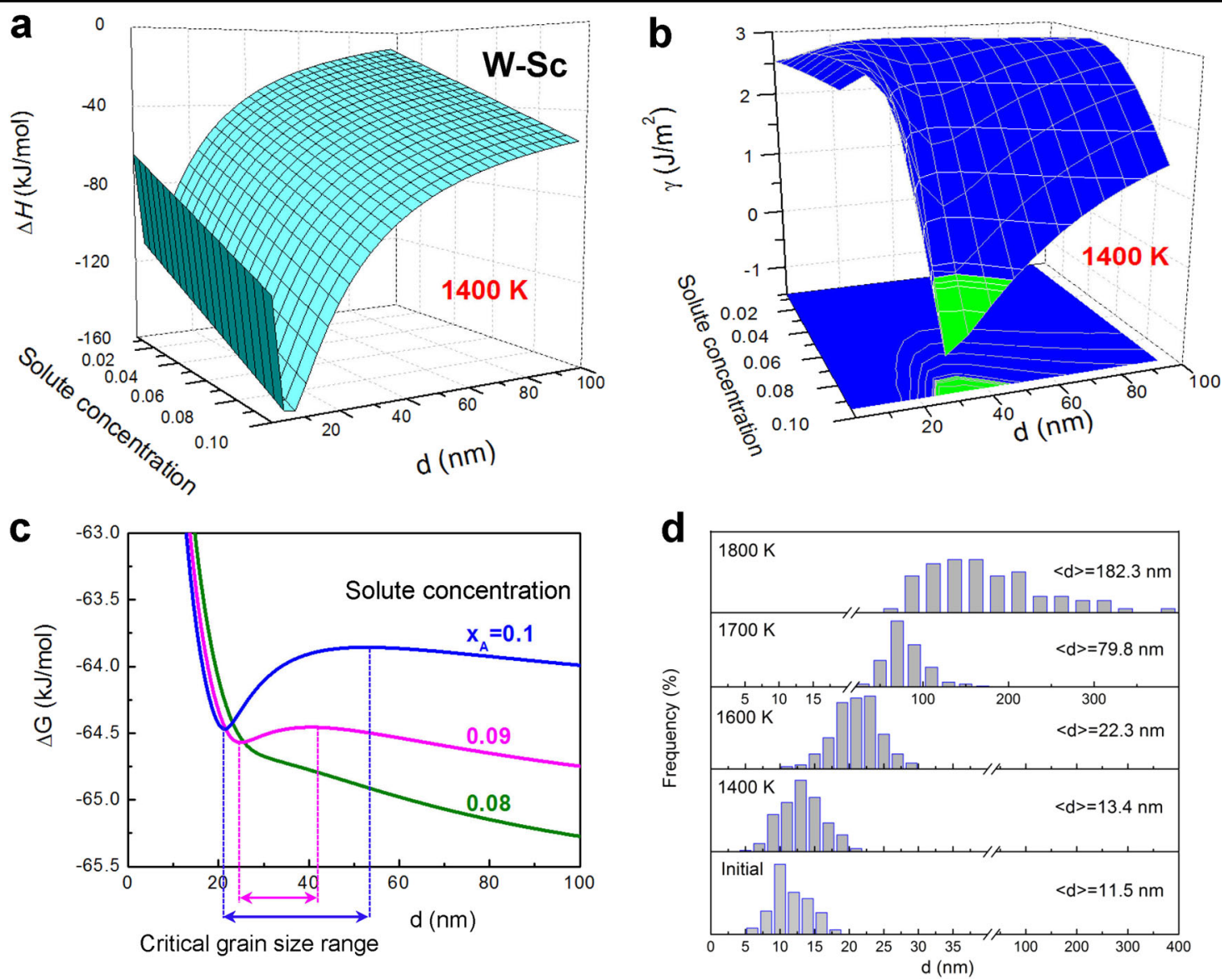

Fig. 11 Design of nanocrystalline W-Sc alloys based on the matching effect of solute concentration and initial grain size. a Segregation enthalpy, $\mathbf{b}$ grain-boundary formation energy and $\mathbf{c}$ change in the Gibbs free energy of the W-Sc nanocrystalline system as a function of the solute concentration, grain size, and temperature, respectively. $\mathbf{d}$ Grain size distributions of the nanocrystalline W-Sc alloys before and after annealing at different temperatures ${ }^{63}$. Reproduced with permission from the Royal Society of Chemistry.

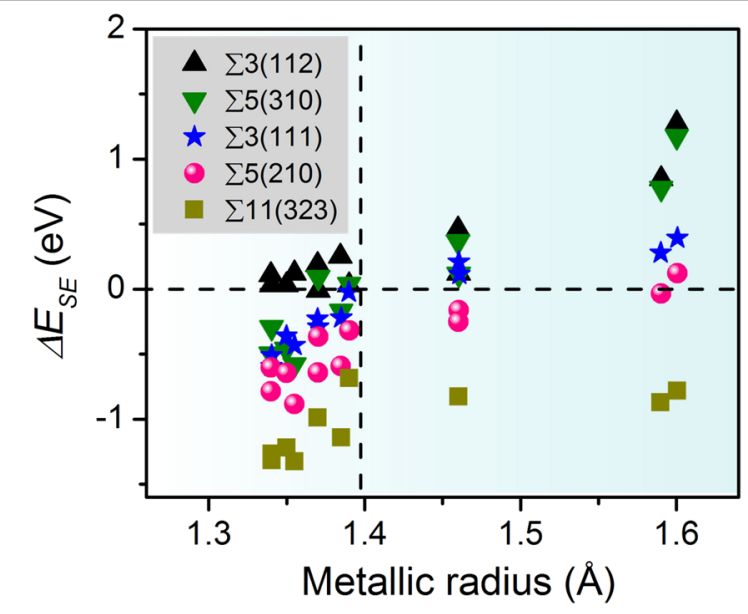

Fig. 12 Dependence of the strengthening energy of solutes on the metallic radii at their most favorable positions for different grain boundaries ${ }^{64}$. an appropriate matching of the solute concentration and initial grain size is required for the solid solution alloy system. The lower the solute concentration, the narrower the critical range of the initial grain size for the structure stabilization at a given temperature should be (Fig. 11c). The model calculations were confirmed quantitatively by the experimental results (Fig. 11d), where a nanocrystalline W-2.6 wt.\% Sc alloy with a highly stable nanograin structure in a broad range from room temperature to $1600 \mathrm{~K}$ was prepared.

The elements that segregate at the $\mathrm{W}$ grain boundaries, on the one hand, inhibit grain growth; on the other hand, they may affect the strength of the grain boundaries. The influences of various transition metals on the strength of different W boundaries were evaluated by first-principles calculations $^{64}$. Figure 12 illustrates the dependence of the strengthening energy $\left(\Delta E_{\mathrm{SE}}\right)$ on the atomic radius of the alloying element at its most favorable site occupation for different types of $\mathrm{W}$ grain boundaries. The positive/ 
negative $\Delta E_{\mathrm{SE}}$ implies the weakening/strengthening of the alloying element on the $\mathrm{W}$ grain boundary. It is shown that the strengthening of the $\mathrm{W}$ grain boundaries is determined by both the segregating element and the grain boundary structure. The calculations suggested that smaller solute atoms act as cohesion enhancers, while larger atoms can be embrittlers of the grain boundaries, probably due to the reduction or increase in the strain in the grain boundary region.

\section{Dispersed particles}

Except for the alloying elements, the particles dispersed in the matrix can also inhibit grain growth effectively by hindering the migration of grain boundaries and dislocation movement. As a result, they can refine the microstructures of $\mathrm{W}-\mathrm{Cu}$ composites and improve their strength. Recently, it was demonstrated that in addition to improving the mechanical properties, dispersed nanoparticles can also enhance the irradiation tolerance $^{65}$. A series of compound particles with high hardness, strength, and thermal stability have been used to fabricate $\mathrm{W}-\mathrm{Cu}$-based composites with fine-grained structures and enhanced mechanical properties. The added hard-phase particles include oxides, carbides, nitrides, and borides ${ }^{12,66-71}$. Compared with the oxides, the carbides have advantages in terms of a better combination of strength, toughness, and thermal and electrical conductivity. In addition, carbides can adsorb free oxygen and thus reduce the oxygen content in the composites, which decreases the brittleness of the material by purifying the interfaces ${ }^{72}$.

\section{Introduction of particles}

Depending on the type of processing, the introduction of particles can be classified into three categories: solid-solid, solid-liquid, and liquid-liquid. The solid-solid method, such as high-energy ball milling, has been widely used to introduce dispersed particles. Studies on the effects of WC and $\mathrm{CeO}_{2}$ on the microstructure and properties of $\mathrm{W}-\mathrm{Cu}$ composites indicated that the addition of these two types of particles with proper amounts can lead to an increase in hardness because of the decrease in grain size of the matrix $^{12}$. At the same time, the thermal and electrical conductivity can also be improved due to the increased densification. However, an excessive addition thereof will affect the dispensability of these particles, leading to a decrease in hardness and electrical conductivity. From a series of W-30 wt.\% $\mathrm{Cu}$ composites with different TiN contents prepared by blending $\mathrm{Cu}$-coated $\mathrm{W}$ powder and $\mathrm{TiN}^{67}$, it was found that a small amount of TiN can prevent the growth of $\mathrm{W}$ grains in the sintering process. The composite exhibited increased hardness and strength but a slight decrease in the electrical conductivity.
Coaddition of the alloying element $\mathrm{Cr}$ and the $\mathrm{ZrC}$ nanoparticles was carried out by the authors, and a notable effect on control of the $\mathrm{W}$ grain growth was obtained in the sintered $\mathrm{W}-\mathrm{Cu}$ composite bulk. It was confirmed that the addition of $\mathrm{Cr}$ in $\mathrm{W}$ can refine the grain structure owing to the effect of phase separation ${ }^{73}$. As shown in Fig. 13a, in the prepared W-Cu composite with the coaddition of $\mathrm{Cr}$ and $\mathrm{ZrC}$, the mean grain size of W was decreased significantly (as fine as $40 \mathrm{~nm}$ ) compared with materials reported previously with the same matrix. A detailed examination shows that the $\mathrm{Cr}$ - and $\mathrm{Zr}$ rich phases tend to concentrate at the grain boundaries and triple junctions, as shown in Fig. 13b-e.

The solid-solid method requires a longer time to generate a homogeneous distribution of the particles in the $\mathrm{W}-\mathrm{Cu}$ matrix. To reduce the process duration and improve the dispersion of the particles, some progress has been made in the solid-liquid method ${ }^{66}$. A type of $\mathrm{W}-\mathrm{Cu}$ composite with a WC interface transition layer was developed (Fig. 14); the layer was formed in situ by coating $\mathrm{C}$ and $\mathrm{Cu}$ onto $\mathrm{W}$ powder in $\operatorname{turn}^{70}$. The effect of WC on the physical properties of the composite was further studied. The results showed that for the W-20 wt.\% Cu composite with the WC transition layer, the thermal conductivity was increased by $\sim 20 \%$ (from 235 to $\left.287.5 \mathrm{~W}(\mathrm{mK})^{-1}\right)$, while the thermal expansion coefficient was decreased from 7.38 to $4.40 \mathrm{ppm} \mathrm{K}^{-1}$. The improvement in the physical properties can be attributed to a good $\mathrm{Cu}$ network and enhanced bonding of the $\mathrm{W}-\mathrm{Cu}$ interfaces by WC. This method seems to be effective regarding the introduction of particles at the interface.

Recently, a novel technique in the scope of solid-solid methods was proposed by us to synthesize nanoscale $\mathrm{W}-\mathrm{Cu}$ composite powders with highly dispersive WC nanoparticles and an adjustable composition ${ }^{74}$. The strategy is based on low-temperature solid-state in situ reactions, where controllable partial decarburization of $\mathrm{WC}$ occurs, assisted by oxides of $\mathrm{W}$ and $\mathrm{Cu}$. As a result, a $\mathrm{W}-\mathrm{Cu}-\mathrm{WC}$ nanocomposite powder with high purity, a homogeneous microstructure and a narrow particle size distribution can be obtained at a temperature as low as $850^{\circ} \mathrm{C}$. In principle, this method is applicable to synthesizing a variety of $\mathrm{W}$-based nanoscale composite powders containing nanoparticles, such as carbides and nitrides. Its advantage is that the bulk composite material prepared by sintering this kind of in situ synthesized nanocomposite powder can have a nanocrystalline structure with a homogeneous distribution of different phases, as shown in Fig. 15. Particularly, the strengthening particles formed by in situ reactions may have a crystallographic orientation relationship with the matrix, which is beneficial to the mechanical properties of bulk composites. If there is a certain proportion of coherent and semicoherent phase 
a

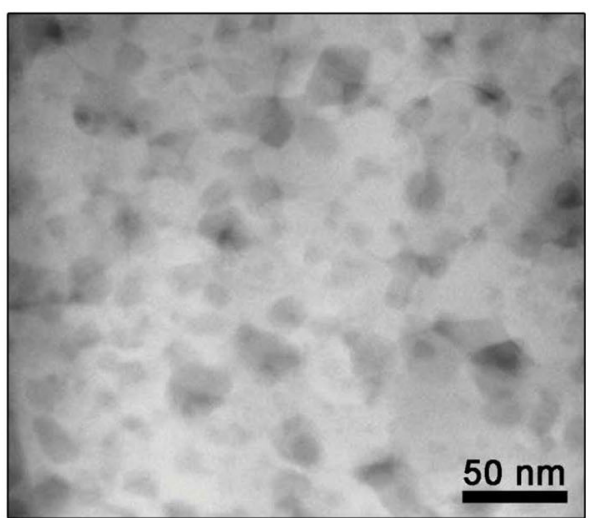

b
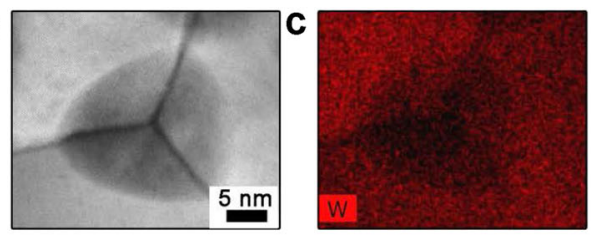

d
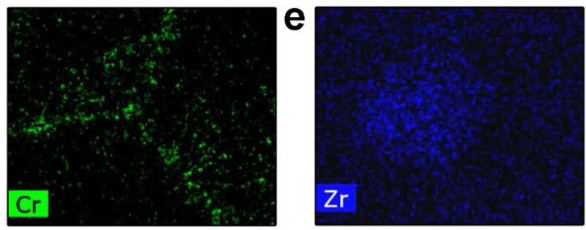

Fig. 13 Characterization of W-Cu composite with coaddition of $\mathrm{Cr}$ and $\mathrm{ZrC}$. a Nanograin structure of W in the W-Cu composite prepared by the coaddition of $\mathrm{Cr}$ and $\mathrm{ZrC}$. $\mathbf{b}-\mathbf{e}$ Element distributions at the grain boundaries of $\mathrm{W}$.
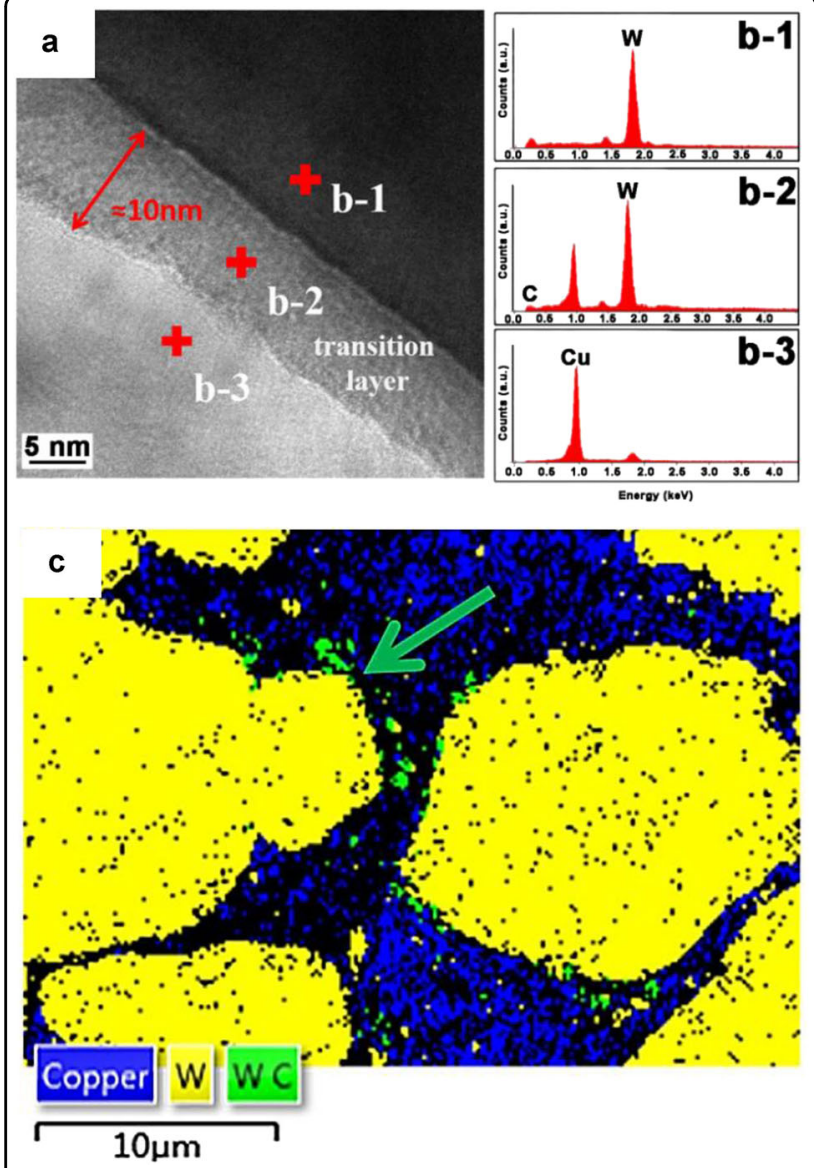

Fig. 14 Characterization of W-Cu composite with a WC interface transition layer prepared by solid-liquid method. a Microstructure of the W-Cu composite with a transition layer at the interface. (b-1)(b-3) Composition analysis of the regions marked in (a). c Electron backscatter diffraction (EBSD) analysis showing the phase distribution map of the $\mathrm{W}-\mathrm{Cu}$ composite with a transition layer ${ }^{70}$.

boundaries that form in the composites, significant enhancement in the fracture strength and toughness can be obtained simultaneously ${ }^{75,76}$.
In the liquid-liquid method, a composite powder with nanoscale particles and a dispersive distribution can be prepared by mixing the components in the liquid phase. As reported, a W-25 wt.\% $\mathrm{Cu}-\mathrm{La}_{2} \mathrm{O}_{3}$ composite powder was prepared by this method ${ }^{69}$, where $\mathrm{La}_{2} \mathrm{O}_{3}$ nanoparticles with sizes of 15-30 nm existed at the surfaces of the $\mathrm{W}$ and $\mathrm{Cu}$ particles and were also distributed within the $\mathrm{Cu}$ (Fig. 16). At a $\mathrm{La}_{2} \mathrm{O}_{3}$ content of $2 \mathrm{wt} . \%$, the electrical conductivity, hardness, and tensile strength of the prepared composite bulk were 52.5\% IACS, $288 \mathrm{HB}$, and $375.9 \mathrm{MPa}$, respectively. At present, the liquid-liquid method is limited to introducing oxides into the $\mathrm{W}-\mathrm{Cu}$ composite. How to introduce other kinds of particles, such as carbides, nitrides, and borides, and make them highly dispersed in the $\mathrm{W}-\mathrm{Cu}$ matrix are still challenging questions for the liquid-liquid method.

\section{Distribution of particles}

The distribution of the introduced particles in the grain interiors or at grain boundaries can have different effects on the properties of the $\mathrm{W}-\mathrm{Cu}$ composites. Fine oxide particles dispersed in $\mathrm{W}$ grains are beneficial, enabling achieving both high strength and plasticity. It is considered that when the hard-phase particles are distributed in the grain interiors, the plasticity increases, while the strength is maintained. However, if the hard-phase particles are distributed mainly at the grain boundaries, the stress concentration will accumulate, which may lead to the formation of a crack source and thus a decrease in the plasticity. Huang et al. ${ }^{77}$ applied a high-pressure SPS technique to produce W oxide particles $(\sim 144 \mathrm{~nm})$ inside the W grains $(\sim 1 \mu \mathrm{m})$. They found that the compressive properties of the composite bulk were enhanced significantly, showing high strength, high plasticity and even some work-hardening. The strengthening effect of the highly dispersed $\mathrm{W}$ oxide particles inside the $\mathrm{W}$ grains is obviously stronger than that by grain refinement, which was performed by processing, such as hot isostatic pressing (HIP), equal channel angular 

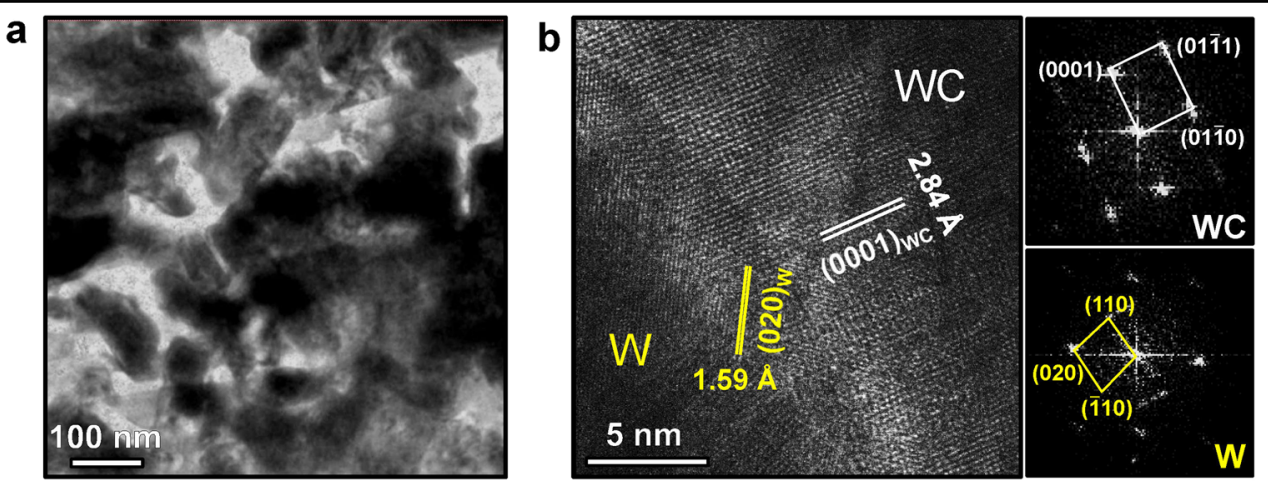

Fig. 15 Characterization of W-Cu composite consolidated with solid-state in situ synthesized raw powders. a Microstructure of the nanocrystalline composite bulk prepared by the in situ synthesized W-Cu-WC nanocomposite powder. b High-resolution image and indexing showing the orientation relationship between the WC particle and W matrix.

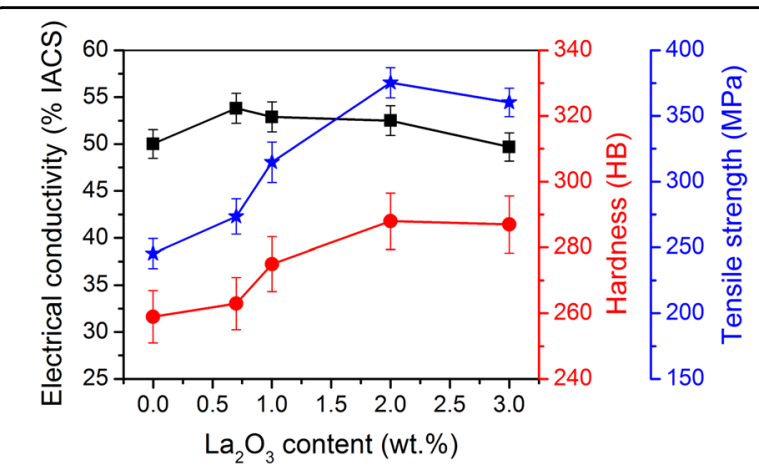

Fig. 16 Effects of $\mathrm{La}_{2} \mathrm{O}_{3}$ content on the electrical conductivity, hardness and tensile strength of the W-Cu composite ${ }^{69}$.

pressing (ECAP) and ECAP + cold rolling (ECAP + CR) with comparable relative density (Fig. 17a). The excellent properties of the composite bulk can be attributed to the well-connected interfaces between the oxides and the matrix grains. The oxide particles can effectively pin dislocations and prevent dislocation motion, forming a microcrack source at the grain boundary (Fig. 17b). Estimated by the calculations, the contribution from the dispersed particles in the grain interiors is $\sim 2.5$ times higher than that of the particles distributing at the grain boundaries. For a W-0.1 wt.\% TiC composite bulk, which was fabricated by combining the wet-chemical method and SPS densification $^{78}$, it was shown that the addition of polyvinylpyrrolidone (PVP) effectively improved the dispersion state of $\mathrm{TiC}$ nanoparticles in the $\mathrm{W}$ grain interior ${ }^{79}$. Thus, the composite with $\mathrm{TiC}$ distributed homogeneously inside the $\mathrm{W}$ grains had much better mechanical properties than those with $\mathrm{TiC}$ mainly distributed at the grain boundaries.

\section{Evaluation of additive effects on microstructures and properties}

Figure 18 provides a summary diagram showing changes in the hardness of $\mathrm{W}-\mathrm{Cu}$ composite materials with the content of various alloying elements. There is a lack of research that aims to determine the influence of alloying elements on the comprehensive properties of $\mathrm{W}-\mathrm{Cu}$ composites. For the physical properties, the existing results show that alloying is generally detrimental. The mechanical properties, taking hardness as an example, can be improved by alloying, except for the addition of Ag. In terms of the existing state, the alloying elements can be divided into two groups: one forms solid solutions, and the other forms compounds with the matrix metals. Elements such as $\mathrm{Zn}$ (lower content), $\mathrm{Zr}$, Pd, and Ni dissolve in $\mathrm{Cu}$ and form a solid solution, which increases the hardness of the composite. Meanwhile, $\mathrm{Fe}, \mathrm{Co}$, and $\mathrm{Zn}$ (higher content) can interact with $\mathrm{W}$ or $\mathrm{Cu}$ and form certain intermetallic compounds, leading to stronger enhancement of the hardness (more than 1.5 times as high as that of the matrix).

The effects of various types of particles on the hardness and electrical conductivity are compared in Fig. 19. This figure indicates that the same type of particle may have different effects on the properties, depending on the content and distribution state, which is caused by the preparation method. First, there is an optimum content for each kind of particle and a specific doping approach. At lower concentrations, the particles can hinder grain growth and have a dispersion strengthening effect. With increasing content, excessive particles may lead to a reduction in the sintering density. Second, highly dispersed fine particles are beneficial for achieving enhanced hardness and electrical conductivity simultaneously. For example, the $\mathrm{La}_{2} \mathrm{O}_{3}$ nanoparticles with high dispersion and fine size, which were introduced by liquid-liquid doping, had a superior effect on the comprehensive performance of the $\mathrm{W}-\mathrm{Cu}$ composites compared with that introduced by the traditional method of mixing and milling. Last, the particles distributed in the $\mathrm{W}$ matrix have less decreasing effect on the electrical conductivity of the composite. The composites with $\mathrm{CeO}_{2}$ and $\mathrm{WC}$ particles 

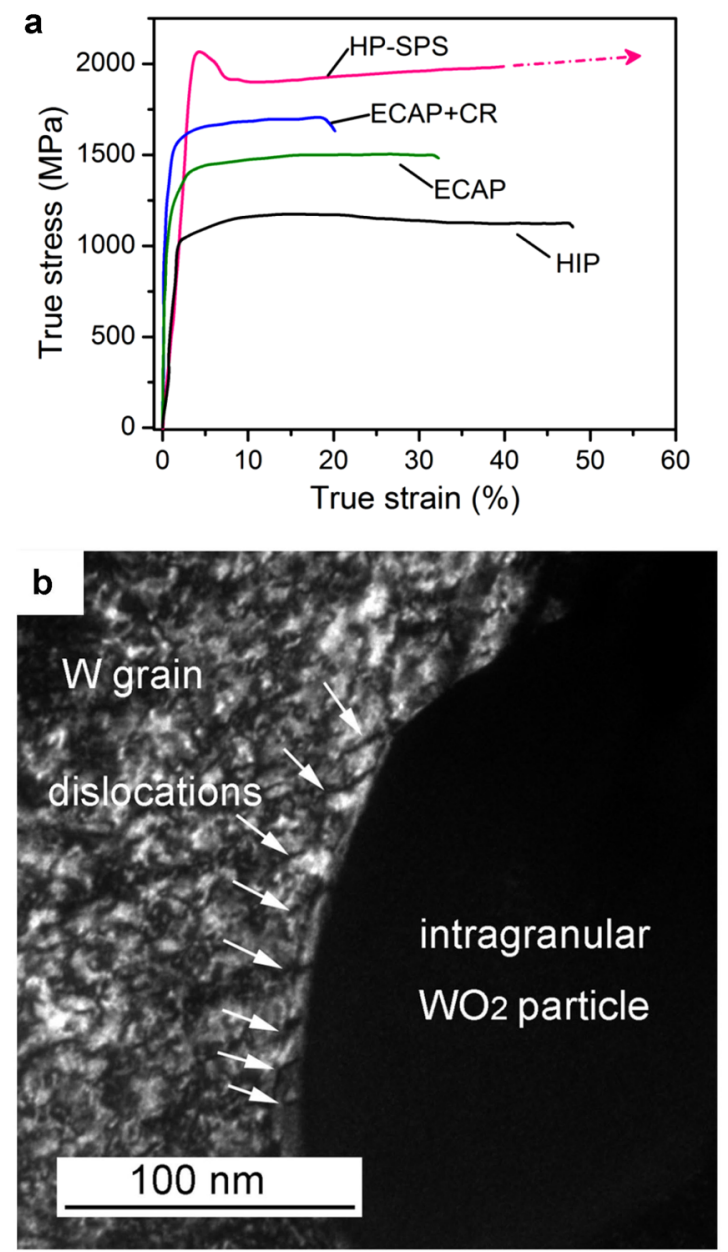

Fig. 17 Mechanical properties and deformed microstructure of W alloys with fine oxide particles dispersed in the grains.

a Comparison of compressive stress-strain curves of W and W-based alloys fabricated by hot isostatic pressing (HIP), equal channel angular pressing (ECAP), and a combination of ECAP and cold rolling (ECAP + CR). b Dislocation alignment at the interface between an intragranular $\mathrm{WO}_{2}$ particle and the $\mathrm{W}$ grain $^{77}$.

distributed mainly in the W skeleton exhibit concurrent improvement of hardness and electrical conductivity within a suitable concentration range.

As analyzed above, both the alloying elements and the introduced particles have significant effects on the microstructure, mechanical properties, and physical properties of the $\mathrm{W}-\mathrm{Cu}$ composites. Because the mechanical and physical properties of $\mathrm{W}-\mathrm{Cu}$ composites are jointly determined by the $\mathrm{W}$ skeleton, $\mathrm{Cu}$ network, and $\mathrm{W} / \mathrm{Cu}$ interface, it is important to increase the strength of both the $\mathrm{W}$ skeleton and $\mathrm{W} / \mathrm{Cu}$ interface while retaining the thermal and electrical conductivities of the $\mathrm{Cu}$ phase, which may contain alloying elements and/or dispersed particles. To achieve excellent comprehensive performance of the composites, the existing state of the alloying elements (solid solution, interfacial segregation,

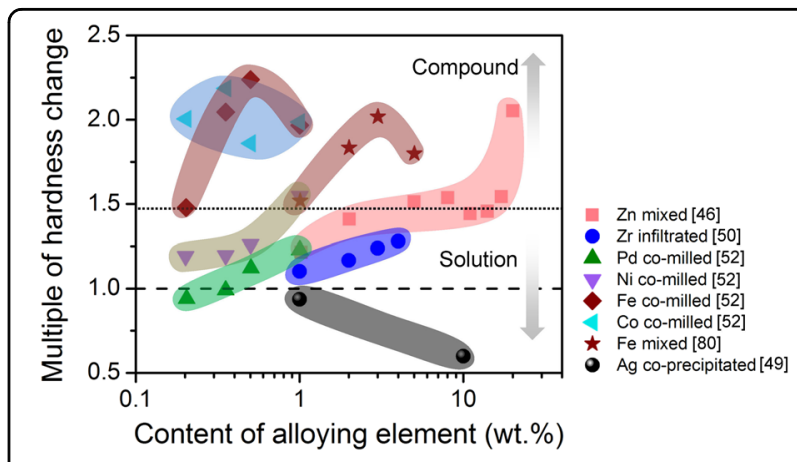

Fig. 18 A summary of the hardness change of the W-Cu composites with the content of various alloying elements, i.e., $\mathrm{Zn}^{46}, \mathrm{Zr}^{50}, \mathrm{Pd}^{52}, \mathrm{Ni}^{52}$ $\mathrm{Fe}^{52,80}, \mathrm{Co}^{52}$, and $\mathrm{Ag}^{49}$.

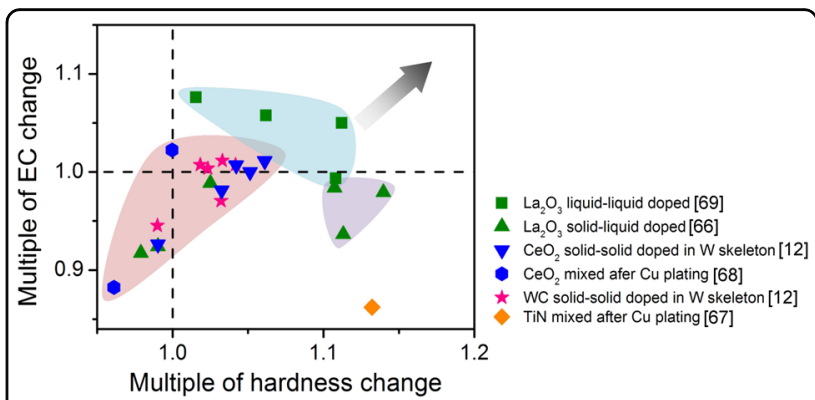

Fig. 19 Comprehensive effects of the introduced particles of $\mathrm{La}_{2} \mathrm{O}_{3}{ }^{66,69}, \mathrm{CeO}_{2}{ }^{12,68}, \mathrm{WC}^{12}$, and $\mathrm{TiN}^{67}$ on the changes in hardness and electrical conductivity (EC).

or precipitation) and the distribution of the introduced particles (inside $\mathrm{W}$ or $\mathrm{Cu}$ grains, at the grain boundaries, or at the $\mathrm{W} / \mathrm{Cu}$ interfaces) should be taken into account carefully and used as factors to modulate the mechanical and physical properties. In particular, the carbides, nitrides, and borides of refractory metals have superior hardness and toughness over metal oxides, especially at high temperatures. Therefore, it is very promising to explore the practicability of introducing these particles into the $\mathrm{W}-\mathrm{Cu}$ matrix to enhance the mechanical properties at high temperatures.

\section{Summary and outlook}

In the present article, the preparation technologies, characteristic microstructures, and additives, as well as their effects on the mechanical and physical properties of the submicron- and nanostructured $\mathrm{W}-\mathrm{Cu}$ composite materials, are reviewed and analyzed. In particular, the methods and principles for the refinement of component structures are evaluated in detail. Discussions are focused on the mechanisms of the effects of additives on the mechanical and physical properties of the composites.

As reviewed, great progress has been made in the development of submicron- and nanostructured $\mathrm{W}-\mathrm{Cu}$ 
composites. However, there are new challenges and important opportunities for future research in the field of $\mathrm{W}-\mathrm{Cu}$ composites. The following promising research issues and directions are proposed.

(1) Scalable technologies for preparing nanostructured $\mathrm{W}-\mathrm{Cu}$-based composites. Although a variety of techniques have been developed for the synthesis of $\mathrm{W}-\mathrm{Cu}$ nanopowders and their sintering densification, scalable methods are highly demanded in practical use. Introducing additives by in situ reactions has been proved to be an effective way for W-based alloys to control grain growth, while investigation of the application of this strategy to $\mathrm{W}-\mathrm{Cu}$-based composites is lacking. The scalable technology to prepare nanoscale $\mathrm{W}-\mathrm{Cu}$ based composite powders should be adjustable in terms of the composition (including additives), existing state of phases, size and distribution of both the matrix particles and additives. Comprehensive optimization of the sintering parameters is still a common issue for the densification of nanocomposite powders to achieve high relative density while maintaining the initial nanostructure of the particles.

(2) Systematic characterizations of comprehensive performance. Different from materials aimed at typical mechanical properties, the desirable $\mathrm{W}-\mathrm{Cu}$ composites need to be characterized by excellent mechanical and physical features. Therefore, tests and evaluations of the comprehensive performance of $\mathrm{W}-\mathrm{Cu}$ composite materials are necessary to extend its applications. With the formation of a database of $\mathrm{W}-\mathrm{Cu}$ composite materials, in which information such as the composition, processing, microstructure, and performance are included, researchers in this field will be benefited in searching for factors that dominate certain properties. Furthermore, it will be helpful to build principles of composition design and processing optimization to obtain advanced composite materials with high comprehensive performance.

(3) Property evaluation under service conditions. Because $\mathrm{W}-\mathrm{Cu}$ composites are attractive for working at high temperatures, the properties measured at room temperature may not be used to evaluate their real performance at service temperatures. Therefore, future studies should pay more attention to the evolution laws of the nanostructure and mechanical and physical performance of $\mathrm{W}-\mathrm{Cu}$ composites with temperature. The factors that may improve the thermal stabilities of the grain structure and comprehensive performance of the composites should be taken into account in the material design. Joint efforts are required to establish the relationship between the composition, processing, and service performance of the $\mathrm{W}-\mathrm{Cu}$ composites.

(4) Cooperative effect of additives on the properties. The effects of alloying elements and introduced particles on the thermal stabilities of the microstructures and mechanical and physical properties require deeper examination. The features of the additives, such as the existing state, size and homogeneity, morphology, and dispersion degree, should be combined to analyze their effect on the microstructure and performance of the composites. In addition, the combination state between the additive and the matrix requires more attention to understand the cooperative effect of the additive on the mechanical and physical properties of the $\mathrm{W}-\mathrm{Cu}$-based composites.

(5) Mechanisms on multiscale for comprehensive performance. Along with experimental investigations, models and simulations must be developed on a multiscale to disclose mechanisms for determining the comprehensive performance of the $\mathrm{W}-\mathrm{Cu}$ composites. As a large majority of experimental studies have been conducted on the microscale for $\mathrm{W}-\mathrm{Cu}$ composites, examinations with insights at the scale of atoms and electrons are especially needed for both experiments and simulations. Modeling assisted by coupling the first-principles with thermodynamic calculations may facilitate a more precise description of the composition effect in the multicomponent system. The molecular dynamics and Monte Carlo simulations may help in understanding the correlation between the microstructural evolution and performance of the composites.

Experimentally, detailed characterizations, e.g., using in situ transmission electron microscopy to examine the mechanical behavior, are particularly useful in disclosing the failure mechanisms of the composites, in which the effects of crystal defects on the formation and propagation of microcracks can be distinguished.

\footnotetext{
Acknowledgements

This work was supported by the National Natural Science Foundation of China (51701007, 51631002, 51425101, and 51621003).
}

Conflict of interest

The authors declare that they have no conflict of interest.

Publisher's note

Springer Nature remains neutral with regard to jurisdictional claims in published maps and institutional affiliations. 
Received: 7 April 2019 Revised: 5 September 2019 Accepted: 6 October 2019.

Published online: 20 December 2019

\section{References}

1. Bhalla, A. K. \& Williams, J. D. A comparative assessment of explosive and other methods of compaction in the production of tungsten-copper composites. Powder Metall. 19, 31-37 (1976).

2. Sebastian, K. V. Properties of sintered and infiltrated tungsten-copper electrical contact material. Int. J. Powder Metall. 17, 297-300 (1981).

3. German, R. M., Hens, K. F. \& Johnson, J. L. Powder metallurgy processing of thermal management materials for microelectronic applications. Int. J. Powder Metall. 30, 205-215 (1994).

4. Dong, L. L., Ahangarkani, M., Chen, W. G. \& Zhang, Y. S. Recent progress in development of tungsten-copper composites: fabrication, modification and applications. Int. J. Refract. Met. Hard Mater. 75, 30-42 (2018).

5. Echlin, M. P. et al. Three-dimensional characterization of the permeability of W-Cu composites using a new "TriBeam" technique. Acta Mater. 64, 307-315 (2014).

6. Raghu, T., Sundaresan, R., Ramakrishnan, P. \& Mohan, T. R. R. Synthesis of nanocrystalline copper-tungsten alloys by mechanical alloying. Mater. Sci. Eng., A 304-306, 438-441 (2001).

7. Moon, I. \& Lee, J. Sintering of W-Cu contact materials with Ni and Co dopants. Powder Metall. Int. 9, $23-24$ (1977).

8. Doré, F., Lay, S., Eustathopoulos, N. \& Allibert, C. H. Segregation of Fe during the sintering of doped W-Cu Alloys. Scr. Mater. 49, 237-242 (2003).

9. Lee, J. S. \& Kim, T. H. Densification and microstructure of the nanocomposite W-Cu powders. Nanostruct. Mater. 6, 691-694 (1995).

10. Johnson, J. L., Brezovsky, J. J. \& German, R. M. Effects of tungsten particle size and copper content on densification of liquid-phase-sintered W-Cu. Metall. Mater. Trans. A 36, 2807-2814 (2005).

11. Stevens, A. Powder-metallurgy solutions to electrical-contact problems. Powder Metall. 17, 331-346 (1974).

12. Yang, X. H., Liang, S. H., Wang, X. H., Xiao, P. \& Fan, Z. K. Effect of WC and $\mathrm{CeO}_{2}$ on microstructure and properties of $\mathrm{W}-\mathrm{Cu}$ electrical contact material. Int. J. Refract. Met. Hard Mater. 28, 305-311 (2010).

13. Bregel, T., Krauss-Vogt, W., Michal, R. \& Saeger, K. E. On the application of W/Cu materials in the fields of power engineering and plasma technology. IEEE Trans. Compon., Hybrids, Manuf. Technol. 14, 8-13 (1991).

14. Frey, P., Klink, N., Michal, R. \& Saeger, K. E. Metallurgical aspects of contact materials for vacuum switching devices. IEEE Trans. Plasma Sci. 17, 734-740 (1989).

15. Wang, W. S. \& Hwang, K. S. The effect of tungsten particle size on the processing and properties of infiltrated W-Cu compacts. Metall. Mater. Trans. A 29, 1509-1516 (1998).

16. Rape, A.r Chanthapan, S., Singh, J. \& Kulkarni, A. Engineered chemistry of Cu-W composites sintered by field-assisted sintering technology for heat sink applications. J. Mater. Sci. 46, 94-100 (2011).

17. Schubert, W. D. Aspects of research and development in tungsten and tungsten alloys. Int. J. Refract. Met. Hard Mater. 11, 151-157 (1992).

18. Duan, L. H., Lin, W. S., Wang, J. L. \& Yang, G. L. Thermal properties of W-Cu composites manufactured by copper infiltration into tungsten fiber matrix. Int. J. Refract. Met. Hard Mater. 46, 96-100 (2014).

19. Li, D. R., Liu, Z. Y., Y Y , Y. \& Wang, E. D. Research on the densification of W-40wt. $\%$ Cu by liquid sintering and hot-hydrostatic extrusion. Int. J. Refract. Met. Hard Mater. 26, 286-289 (2008).

20. Shen, Q., Zhou, D. Q., Zhang, J., Luo, G. Q. \& Zhang, L. M. Study on preparation and property of porous tungsten via tape-casting. Int. J. Refract. Met. Hard Mater. 69, 27-30 (2017).

21. Zhang, Z. H. et al. Generalized fabrication of nanoporous metals (Au, Pd, Pt, Ag, and $\mathrm{Cu}$ ) through chemical dealloying. J. Phys. Chem. C 113, 12629-12636 (2009).

22. Hou, C. et al. Nanoporous tungsten with tailorable microstructure and high thermal stability. Int. J. Refract. Met. Hard Mater. 77, 128-131 (2018).

23. Zhang, Q., Liang, S. H., Hou, B. Q. \& Zhuo, L. C. The effect of submicron-sized initial tungsten powders on microstructure and properties of infiltrated W25wt.\% Cu alloys. Int. J. Refract. Met. Hard Mater. 59, 87-92 (2016).

24. Zhang, Q., Liang, S. H. \& Zhuo, L. C. Ultrafine-grained W-25 wt-\%Cu composite with superior high-temperature characteristics. Mater. Sci. Technol. 33, 1-7 (2017).
25. Maneshian, M. H. \& Simchi, A. Solid state and liquid phase sintering of mechanically activated W-20wt.\% Cu powder mixture. J. Alloy. Compd. 463, 153-159 (2008).

26. Ryu, S. S., Kim, Y. D. \& Moon, I. H. Dilatometric analysis on the sintering behavior of nanocrystalline W-Cu prepared by mechanical alloying. J. Alloy. Compd. 335, 233-240 (2002)

27. Kim, J. C., Ryu, S. S. \& Moon, I. H. Nanostructural characteristics and sintering behavior of W-Cu composite powder prepared by mechanical alloying. J. Adv. Mater. 31, 37-44 (1999).

28. Ryu, S. S., Park, H. R., Kim, Y. D. \& Hong, H. S. Effect of ball-milling time on structural characteristics and densification behavior of $\mathrm{W}-\mathrm{Cu}$ composite powder produced from $\mathrm{WO}_{3}-\mathrm{CuO}$ powder mixtures. Int. J. Refract. Met. Hard Mater. 65, 39-44 (2017)

29. Fan, J. L., Liu, T., Zhu, S. \& Han, Y. Synthesis of ultrafine/nanocrystalline W(30-50)Cu composite powders and microstructure characteristics of the sintered alloys. Int. J. Refract. Met. Hard Mater. 30, 33-37 (2012).

30. Liang, S. H., Wang, X. H., Wang, L. L., Cao, W. C. \& Fang, Z. K. Fabrication of CuW pseudo alloy by W-CuO nanopowders. J. Alloy. Compd. 516, 161-166 (2012).

31. Wan, L., Cheng, J. G., Fan, Y. M., Liu, Y. \& Zheng, Z. J. Preparation and properties of superfine W-20Cu powders by a novel chemical method. Mater. Des. $\mathbf{5 1}$ 136-140 (2013).

32. Azar, G. T. P., Rezaie, H. R., Gohari, B. \& Razavizadeh, H. Synthesis and densification of W-Cu, W-Cu-Ag and W-Ag composite powders via a chemical precipitation method. J. Alloy. Compd. 574, 432-436 (2013).

33. Yoon, E. S., Lee, J. S., Oh, S. T. \& Kim, B. K. Microstructure and sintering behavior of W-Cu nanocomposite powder produced by thermo-chemical process. Int. J. Refract. Met. Hard Mater. 20, 201-206 (2002).

34. Hong, S. H. \& Kim, B. K. Fabrication of W-20wt\% Cu composite nanopowder and sintered alloy with high thermal conductivity. Mater. Lett. 57, 2761-2767 (2003).

35. Li, Y. P. et al. Properties of W-Cu composite powder produced by a thermomechanical method. Int. J. Refract. Met. Hard Mater. 21, 259-264 (2003).

36. $\mathrm{X}, \mathrm{X}$. L. et al. Preparation of W-Cu nano-composite powder using a freezedrying technique. Int. J. Refract. Met. Hard Mater. 28, 301-304 (2010).

37. Zhou, Y. et al. Microstructure and properties of fine grained $\mathrm{W}-15 \mathrm{wt} . \% \mathrm{Cu}$ composite sintered by microwave from the sol-gel prepared powders. J. Alloy. Compd. 547, 18-22 (2013).

38. Guo, Y. J. et al. Rapid consolidation of ultrafine grained W-30wt.\%Cu composites by field assisted sintering from the sol-gel prepared nanopowders. J. Alloy. Compd. 724, 155-162 (2017).

39. Qiu, W. T., Pang, Y., Xiao, Z. \& Li, Z. Preparation of W-Cu alloy with high density and ultrafine grains by mechanical alloying and high pressure sintering. Int. J. Refract. Met. Hard Mater. 61, 91-97 (2016).

40. Guo, Y. L. et al. Fabrication of W-Cu composites by microwave infiltration. J. Alloy. Compd. 492, L75-L78 (2010).

41. Luo, S. D. et al. Microwave sintering W-Cu composites: analyses of densification and microstructural homogenization. J. Alloy. Compd. $\mathbf{4 7 3}$, L5-L9 (2009).

42. $\mathrm{Xu}$, L. et al. Fabrication of tungsten-copper alloys by microwave hot pressing sintering. J. Alloy. Compd. 658, 23-28 (2016).

43. Shi, X. L., Yang, H. \& Wang, S. Spark plasma sintering of W-15Cu alloy from ultrafine composite powder prepared by spray drying and calciningcontinuous reduction technology. Mater. Charact. 60, 133-137 (2009).

44. Elsayed, A. et al. Experimental investigations on the synthesis of $\mathrm{W}-\mathrm{Cu}$ nanocomposite through spark plasma sintering. J. Alloy. Compd. 639, 373-380 (2015).

45. Sabirov, I. \& Pippan, R. Formation of a W-25\%Cu nanocomposite during high pressure torsion. Scr. Mater. 52, 1293-1298 (2005).

46. Chen, P., Luo, G. Q., Li, M. J., Shen, Q. \& Zhang, L. M. Effects of Zn additions on the solid-state sintering of W-Cu composites. Mater. Des. 36, 108-112 (2012).

47. Chen, P., Shen, Q., Luo, G. Q., Li, M. J. \& Zhang, L. M. The mechanical properties of W-Cu composite by activated sintering. Int. J. Refract. Met. Hard Mater. 36 220-224 (2013)

48. Chen, P., Luo, G. Q., Shen, Q., Li, M. J. \& Zhang, L. M. Thermal and electrical properties of W-Cu composite produced by activated sintering. Mater. Des. 46, 101-105 (2013).

49. Azar, G. T. P., Rezaie, H. R. \& Razavizadeh, H. Synthesis and consolidation of WCu composite powders with silver addition. Int. J. Refract. Met. Hard Mater. 31, 157-163 (2012).

50. Yang, X. H., Zou, J. T., Xiao, P. \& Wang, X. H. Effects of Zr addition on properties and vacuum arc characteristics of Cu-W alloy. Vacuum 106, 16-20 (2014). 
51. Wang, J. W., Fan, J. L. \& Gong, H. R. Effects of $\mathrm{Zr}$ alloying on cohesion properties of CuM interfaces. J. Alloy. Compd. 661, 553-556 (2016).

52. Johnson, J. L. \& German, R. M. Phase equilibria effects on the enhanced liquid phase sintering of tungsten-copper. Metall. Trans. A 24 2369-2377 (1993).

53. Johnson, J. L. Activated liquid phase sintering of $\mathrm{W}-\mathrm{Cu}$ and $\mathrm{Mo}-\mathrm{Cu}$. Int. J. Refract. Met. Hard Mater. 53, 80-86 (2015).

54. Detor, A. J. \& Schuh, C. A. Grain boundary segregation, chemical ordering and stability of nanocrystalline alloys: atomistic computer simulations in the $\mathrm{Ni}-\mathrm{W}$ system. Acta Mater. 55, 4221-4232 (2007).

55. Chookajorn, T. \& Schuh, C. A. Thermodynamics of stable nanocrystalline alloys: A Monte Carlo analysis. Phys. Rev. B 89, 064102 (2014).

56. Xing, W. T., Kalidindi, A. R. \& Schuh, C. A. Preferred nanocrystalline configurations in ternary and multicomponent alloys. Scr. Mater. 127, 136-140 (2017).

57. Chookajorn, T., Murdoch, H. A. \& Schuh, C. A. Design of stable nanocrystalline alloys. Science 337, 951-954 (2012).

58. Chookajorn, T. \& Schuh, C. A. Nanoscale segregation behavior and hightemperature stability of nanocrystalline W-20at.\%Ti. Acta Mater. 73, 128-138 (2014).

59. Ren, C., Koopman, M., Zak Fang, Z., Zhang, H. \& van Devener, B. A study on the sintering of ultrafine grained tungsten with Ti-based additives. Int. J. Refract Met. Hard Mater. 65, 2-8 (2017).

60. Chai, R., Koopman, M., Fang, Z. Z. \& Zhang, H. The effects of atmosphere on the sintering of ultrafine-grained tungsten with Ti. JOM 68, 1-5 (2017).

61. Song, X. Y., Zhang, J. X., Li, L. M., Yang, K. Y. \& Liu, G. Q. Correlation of thermodynamics and grain growth kinetics in nanocrystalline metals. Acta Mater. 54, 5541-5550 (2006).

62. Xu, W. W., Song, X. Y., Lu, N. D. \& Huang, C. Thermodynamic and experimental study on phase stability in nanocrystalline alloys. Acta Mater. 58, 396-407 (2010).

63. Tang, F. et al. Solute segregation and thermal stability of nanocrystalline solid solution systems. Nanoscale 11, 1813-1826 (2019).

64. $\mathrm{Wu}, \mathrm{X}$. B. et al. First-principles determination of grain boundary strengthening in tungsten: dependence on grain boundary structure and metallic radius of solute. Acta Mater. 120, 315-326 (2016).

65. El-Atwani, O. et al. In-situ irradiation tolerance investigation of high strength ultrafine tungsten-titanium carbide alloy. Acta Mater. 164 547-559 (2019).

66. Qian, K., Liang, S. H., Peng, X. \& Wang, X. In situ synthesis and electrical properties of CuW- $\mathrm{La}_{2} \mathrm{O}_{3}$ composites. Int. J. Refract. Met. Hard Mater. 31, 147-151 (2012).
67. Huang, L. M. et al. Effects of TiN nanoparticles on the microstructure and properties of W-30Cu composites prepared via electroless plating and powder metallurgy. Mater. Des. 81, 39-43 (2015).

68. Lu, Z. L. et al. Fabrication of $\mathrm{W}-\mathrm{Cu} / \mathrm{CeO}_{2}$ composites with excellent electric conductivity and high strength prepared from copper-coated tungsten and Ceria powders. Mater. Sci. Eng., A 626, 61-66 (2015).

69. Li, J. W. et al. Microstructure and properties characterization of $\mathrm{W}-25 \mathrm{Cu}$ composite materials liquid-liquid doped with $\mathrm{La}_{2} \mathrm{O}_{3}$. Int. J. Refract. Met. Hard Mater. 71, 115-121 (2017)

70. Zhang, C. C. et al. Synthesis and thermal conductivity improvement of W-Cu composites modified with WC interfacial layer. Mater. Des. 127, 233-242 (2017).

71. Huang, L. M., Luo, L. M., Cheng, J. G., Zhu, X. Y. \& Wu, Y. C. The influence of TiB content on microstructure and properties of $\mathrm{W}-30 \mathrm{Cu}$ composites prepared by electroless plating and powder metallurgy. Adv. Powder Technol. 26, 1058-1063 (2015).

72. Zou, J., Ma, H. B., D'Angio, A. \& Zhang, G. J. Tungsten carbide: a versatile additive to get trace alkaline-earth oxide impurities out of $\mathrm{ZrB}_{2}$ based ceramics. Scr. Mater. 147, 40-44 (2018).

73. Park, M. \& Schuh, C. A. Accelerated sintering in phase-separating nanostructured alloys. Nat. Commun. 6, 6858 (2015).

74. Li, Y. R., Hou, C., Lu, H., Liang, S. H. \& Song, X. Y. WC strengthened W-Cu nanocomposite powder synthesized by in-situ reactions. Int. J. Refract. Met Hard Mater. 79, 154-157 (2019).

75. Song, $X$. Y. et al. Effect of interfacial characteristics on toughness of nanocrystalline cemented carbides. Acta Mater. 61, 2154-2162 (2013).

76. Liu, X. W. et al. Complexions in WC-Co cemented carbides. Acta Mater. 149, 164-178 (2018)

77. Huang, L. et al. In situ oxide dispersion strengthened tungsten alloys with high compressive strength and high strain-to-failure. Acta Mater. 122, 19-31 (2017).

78. Xia, M. et al. Synthesis of TiCM core-shell nanoparticles by precipitate-coating process. J. Nucl. Mater. 430, 216-220 (2012).

79. Lang, S. T. et al. Preparation and microstructure characterization of W-0.1 wt.\% TiC alloy via chemical method. Int. J. Refract. Met. Hard Mater. 55, 33-38 (2016).

80. Mohammad, K. S., Rahmat, A. \& Ismail, A. B. The effects of Fe additions on the liquid phase sintering of W-bronze composites. J. Alloy. Compd. 482, 447-454 (2009).

81. http://www.torreyhillstech.com/cuwdata.html.

82. Abbaszadeh, H., Masoudi, A., Safabinesh, H. \& Takestani, M. Investigation on the characteristics of micro- and nano-structured W-15wt.\%Cu composites prepared by powder metallurgy route. Int. J. Refract. Met. Hard Mater. 30, 145-151 (2012). 